\title{
Real-time, controlled OH-initiated oxidation of biogenic secondary organic aerosol
}

\author{
J. G. Slowik ${ }^{1,2}$, J. P. S. Wong ${ }^{1}$, and J. P. D. Abbatt ${ }^{1}$ \\ ${ }^{1}$ Department of Chemistry, University of Toronto, Toronto, ON, Canada \\ ${ }^{2}$ Laboratory of Atmospheric Chemistry, Paul Scherrer Institute, Villigen, Switzerland \\ Correspondence to: J. G. Slowik (jay.slowik@psi.ch) \\ Received: 2 March 2012 - Published in Atmos. Chem. Phys. Discuss.: 26 March 2012 \\ Revised: 5 October 2012 - Accepted: 8 October 2012 - Published: 29 October 2012
}

\begin{abstract}
The chemical complexity of atmospheric organic aerosol (OA) requires novel methods for characterization of its components and description of its atmospheric processing-induced transformations. We present the first field deployment of the Toronto Photooxidation Tube (TPOT), a field-deployable flow reactor for the controlled exposure of ambient aerosol to $\mathrm{OH}$ radicals. The system alternates between sampling of (1) (unreacted) ambient aerosol, (2) aerosol exposed to UV light and subjected to a $\sim 4$ to $10^{\circ} \mathrm{C}$ temperature increase, and (3) aerosol that is oxidized by $\mathrm{OH}$ (in addition to the aforementioned UV exposure/temperature increase). This allows both characterization of the aging process and classification of aerosol in terms of its volatility and reaction-based properties. Summertime measurements by an aerosol mass spectrometer coupled to the TPOT were performed in the remote forest of western Canada, resulting in aerosol dominated by biogenic secondary organic aerosol. Volatilization/UV exposure resulted in an approximately 10 to $25 \%$ decrease in organic mass and resulted in a slight increase in oxygenation. $\mathrm{OH}$ oxidation resulted in a further organic mass decrease (additional $\sim 25 \%$ ) and yielded an aerosol with O:C values comparable to those characteristic of low volatility, highly oxygenated OA. Most OH-induced changes occurred within $\sim 3$ dayequivalents of atmospheric processing, with further reactions generally proceeding at a greatly reduced rate. Positive matrix factorization (PMF) analysis of the TPOT data yielded five factors. One factor is related to primary biomass burning organic aerosol, while the others describe oxygenated organic aerosol (OOA) components in terms of reactivity and volatility: (1) volatile and reactive; (2) non-volatile and reactive; (3) non-volatile and reactive early-generation product;
\end{abstract}

(4) non-volatile and non-reactive product. This PMF classification of aerosol components directly in terms of reactivity and volatility is enabled by the TPOT-modulated perturbation of aerosol composition, and is not otherwise accessible. The particle-phase reaction end products have mass spectra similar to the low-volatility oxygenated organic aerosol (LV-OOA) factors widely reported in the literature, providing supporting evidence for aged organic aerosol formation from $\mathrm{OH}$-driven oxidation processes.

\section{Introduction}

Atmospheric aerosols have important effects on climate, visibility, and human health. However, quantification of such effects remains highly uncertain due in part to challenges in characterizing the organic aerosol (OA) fraction. Such difficulties include the large number of atmospheric organic compounds, many of which cannot presently be identified or isolated, wide range of emissions sources, and myriad pathways for atmospheric OA production and/or processing.

OA can be directly emitted (primary organic aerosol, POA) from sources such as biomass burning and anthropogenic combustion. Alternatively, volatile organic compounds (VOCs) may be emitted by biogenic sources, biomass burning, or anthropogenic activities, and are then oxidized in the atmosphere to form lower-volatility products that partition to the particle phase, forming secondary organic aerosol (SOA) (Kanakidou et al., 2005; de Gouw and Jimenez, 2009; Hallquist et al., 2009). POA and SOA from different sources can mix and become further oxidized by heterogeneous reaction with oxidizing species such as $\mathrm{OH}$ radicals. Further, 
a significant fraction of ambient OA, whether POA or SOA, is semivolatile and may partition back to the gas phase in response to dilution and/or temperature changes, become further oxidized through gas-phase reactions, and then re-enter the particle phase. All the while, the preexisting OA is subject to continuous injections of fresh POA, SOA, and SOA precursors, which in turn undergo the atmospheric processing described above. The resulting OA is a highly complex mixture formed from disparate sources and affected by a wide array of atmospheric processing mechanisms.

Several strategies have been introduced to simplify, isolate, and/or deconvolve these sources and processes. Factor analysis techniques applied to aerosol composition are frequently used for source apportionment. Such approaches include chemical mass balance (e.g. Hidy and Friedlander, 1971; Schauer et al., 1996; Hannigan et al., 2005; Chow et al., 2007), which represents the data as a linear combination of predetermined, static factors, and positive matrix factorization (PMF) (e.g. Paatero and Tapper, 1994; Zhao and Hopke, 2006; Lanz et al. 2007; Ulbrich et al., 2009), which utilizes measurement uncertainties and does not require a priori knowledge of the factor profiles. Hybrid approaches, such as PMF with one or more fixed factors, have also been utilized (Lanz et al., 2008), as have custom models based on known tracers, variable factors, etc. (Wahlin 2003; Zhang et al., 2005; Christensen et al., 2006). For all of these approaches, a central challenge is the source complexity and constantly changing nature (via gas/particle partitioning and chemical reactivity) of the measured aerosol. Descriptions of SOA generation and/or aging are particularly challenging. For example, PMF of data from the Aerodyne aerosol mass spectrometer (AMS), typically describes SOA as a linear combination of semivolatile and low-volatility oxygenated organic aerosol, however more detailed information about reactivity, volatility, sources, etc. is unavailable in the absence of other integrated measurements, such as VOCs (Slowik et al., 2010) or with an online thermodenuder (Huffman et al., 2009).

In contrast, laboratory-based methods potentially allow for controlled aging processes and emission sources, but can be challenging to extrapolate to the atmosphere. Smog chambers provide a laboratory-based method for controlled exposure of model compounds or selected source emissions to oxidizing species. Common model compounds studied include isoprene, $\alpha$-pinene, or other terpenes as surrogates for biogenic emissions, and aromatic species such as toluene as surrogates for anthropogenic combustion. Alternatively, source emissions such as wood burning and diesel vehicles may be injected directly into the smog chamber, and then aged under controlled conditions (Grieshop et al., 2009; Mentel et al., 2009; Chirico et al., 2010). Such analysis of model compounds and specific sources allows for isolation of particular reaction systems, however simplification of the reactive system and/or increased concentrations relative to ambient conditions make it challenging to directly extrapolate such results to the atmosphere.

The methods described above have shown that oxidative aging tends to move $\mathrm{OA}$ from a less oxygenated, semivolatile state to a more oxygenated, low-volatility state. However, the timescales over which this occurs and the associated mechanisms remain unclear. Further, in ambient studies such changes must generally be inferred from complex datasets, in which it is difficult to segregate the relative effects of different sources, atmospheric reactions, and partitioning. Here we employ a complementary approach to the characterization of atmospheric aerosol aging, namely oxidation of directly sampled ambient aerosol by $\mathrm{OH}$ radicals using the Toronto Photooxidation Tube (TPOT). This retains the real-world sources and complexity of ambient measurements while allowing a controlled aging environment. Similar flowtube systems have previously been used to measure the reactivity of ambient urban aerosol (George et al., 2008), estimate the SOA-forming potential model compounds (Kang et al., 2011), and characterize the evolution of laboratory biomass burning emissions (Cubison et al., 2011). They have also been applied to studies of oxidative aging of laboratory aerosol (George et al., 2007; Kroll et al., 2009; George and Abbatt, 2010; Kessler et al., 2010; Lambe et al., 2011a, b). In the TPOT, aging is conducted in a flowtube with a residence time on the order of minutes and the system rapidly switches between reacted and unreacted conditions, which enables highly timeresolved measurements of aerosol aging. The resulting mass spectral changes due to oxidative processing are characterized in terms of selected $\mathrm{m} / \mathrm{z}$ and using the PMF analysis technique. Here we discuss deployment of the TPOT during summer in a forested region known for high levels of biogenic aerosol formation without significant anthropogenic pollution. We address the following questions: (1) Does OH oxidation lead to mass loss of biogenic organic aerosol? (2) What is the character of the mass spectral response, and what insight does it provide regarding the oxidation mechanism? (3) Can PMF analysis demonstrate how different fractions of the biogenic aerosol respond to $\mathrm{OH}$ oxidation?

\section{Materials and methods}

\subsection{Sampling location}

Measurements were conducted as part of the Whistler Aerosol and Cloud Study (WACS 2010, 15 June to 28 July 2010). The TPOT system was deployed at the Raven's Nest station (1320 m a.s.1.) on Whistler Mountain in Whistler, BC, Canada $\left(50.08^{\circ} \mathrm{N}, 122.95^{\circ} \mathrm{W}\right)$. Whistler is located in the remote Canadian forest, approximately $120 \mathrm{~km}$ north of Vancouver. The Raven's Nest site was located in the forest, approximately $450 \mathrm{~m}$ below treeline. A detailed overview of the WACS 2010 campaign is presented elsewhere (Macdonald et al., 2012). Organic aerosol in the Whistler area has 
previously been shown to be strongly influenced by biogenic emissions during the late spring and early summer (e.g. Leaitch et al., 2009; Sun et al., 2009; Schwartz et al., 2010; Takahama et al., 2011; Leaitch et al., 2011). Later in the summer, regional forest fire emissions can also influence the site (McKendry et al., 2011; Takahama et al., 2011). The sampling period for WACS 2010 was chosen to maximize biogenic influences, while minimizing biomass burning ones. As discussed in the results section, this strategy was mostly successful, with the exception of a regional biomass burning event during the last few days of the study. A large biogenic event with organic aerosol levels approaching $6.5 \mu \mathrm{g} \mathrm{m}^{-3}$ was observed from July 6 to 10, while significant local formation of SOA from monoterpene oxidation observed in the diurnal cycles of 13 to 21 July (Macdonald et al., 2012).

The TPOT was housed in an unused single-story restaurant at the Raven's Nest site. The sampling inlet was located approximately $0.5 \mathrm{~m}$ above the roof of the building. Air was continuously sampled through this inlet at $1100 \mathrm{sccm}$, passing through $3 \mathrm{~m}$ of $6 \mathrm{~mm}$ o.d. stainless steel tubing before being introduced into the TPOT. The sampling lines were electrochemically coated with amorphous silicon (SilcoTek, Bellefonte, PA, USA) to minimize adsorptive losses of volatile organic compounds. Controlled $\mathrm{OH}$-initiated oxidation was performed in the TPOT system (see Sect. 2.2), and the resulting particle composition was measured by aerosol mass spectrometry (see section 2.3).

\subsubsection{Toronto Photooxidation Tube (TPOT)}

The TPOT is conceptually based on flow reactor systems previously described and characterized in the literature (George et al., 2007; Lambe et al., 2011a), however the system used in the present study has been significantly upgraded in terms of reactor geometry (higher volume/surface ratio, improved injection/sampling port configuration) and material (most glass and copper surfaces replaced with silicon-coated steel). A schematic of the system is shown in Fig. 1. All surfaces in the system that contact ambient air are coated with the amorphous silicon material described in Sect. 2.1, with the exception of a Pyrex mixing volume and valve systems, discussed below. Sampled ambient air (1100 sccm), a humidified flow $\left(\mathrm{N}_{2}\right.$ passed through a bubbler) maintaining the entire TPOT system at $40 \% \mathrm{RH}$, and a mixed $\mathrm{N}_{2} / \mathrm{O}_{2}$ flow are combined in a Pyrex mixing volume (residence time $\sim 1 \mathrm{~min}$ ). The $\mathrm{N}_{2} / \mathrm{O}_{2}$ flow is either irradiated by a lamp at $185 \mathrm{~nm}$ to produce $\mathrm{O}_{3}$, or bypasses the lamp system. The $\mathrm{N}_{2} / \mathrm{O}_{2}$ path is controlled by an automatic 4-way valve system that switches between conditions every $12 \mathrm{~min}$. To maintain system stability, flow is continuously maintained through both the lamp and lampbypass lines, with one line introduced into the TPOT and the other exhausted to a pump. Ozone concentrations are monitored in the exhaust line using a Model 202 Ozone Analyzer (2B Technologies, Inc., Boulder, CO, USA).

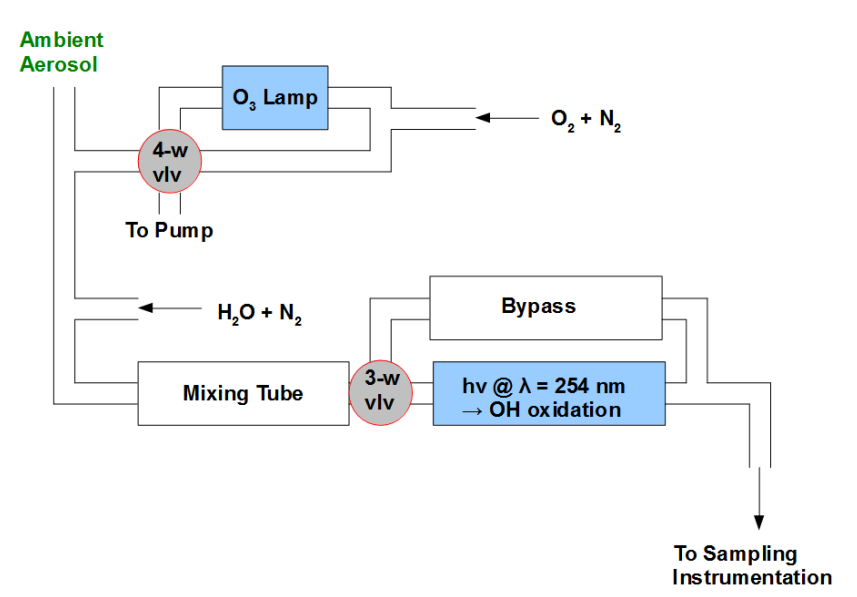

Fig. 1. Schematic diagram of the TPOT system. "4-w vlv" and " $3-w$ vlv" denote the automatic 4-way and manual 3-way valves, respectively.

After the mixing chamber, particles pass into the reaction zone. This consists of a silicon-coated stainless steel tube $(11 \mathrm{~cm}$ o.d. $\times 29 \mathrm{~cm}$ length $)$ with 4-point injection and sampling configurations on the entrance and exit flanges. A UV lamp emitting at $254 \mathrm{~nm}$ is located on the center axis of the tube, and is surrounded by quartz housing. A $\sim 20$ slpm flow of air is maintained between the lamp and the housing to prevent lamp overheating and minimize lamp-induced temperature increases in the flowtube. Residence time in the reaction zone is approximately $1 \mathrm{~min}$, and the surface area-to-volume ratio is approximately $1 / 3 \mathrm{~cm}^{-1}$. Alternatively, a manual 3way valve can be used to send particles through a bypass flow tube system that is identical in all ways to the reaction zone, except that the quartz housing contains no lamp. After passing through the reaction zone or reaction bypass, particles were sampled by an aerosol mass spectrometer (C-ToFAMS, see section 2.3), as well as a differential mobility analyzer coupled to a condensation particle counter and a cloud condensation nuclei counter, as discussed elsewhere (Wong et al., 2011). The transit time from the TPOT exit to the AMS is approximately $30 \mathrm{~s}$.

The $\mathrm{OH}$ concentration in the TPOT is controlled by varying the $\mathrm{O}_{3}$ concentration in the $\mathrm{N}_{2} / \mathrm{O}_{2}$ flow. Steady-state $\mathrm{OH}$ concentrations are determined by calibration experiments in which the decay of methyl-ethyl-ketone (MEK) is measured using a time-of-flight proton transfer reaction mass spectrometer (ToF-PTRMS, Ionicon Analytik, Innsbruck, Austria). This allowed formation of an empirical relationship between $\mathrm{O}_{3}$ concentration and $\mathrm{OH}$ exposure. Because the ToF-PTRMS was not routinely available, reactor stability was periodically monitored by introducing $145 \mathrm{~nm}$ bis(2-ethylhexyl) sebacate $\left(\mathrm{C}_{26} \mathrm{H}_{50} \mathrm{O}_{4}\right.$, BES) particles into the TPOT immediately before or after an MEK calibration at the same conditions. BES is an organic liquid with wellcharacterized heterogeneous $\mathrm{OH}$ reactivity (George et al., 
2007). This calibration allowed the generation of an empirical relationship between the MEK-calibrated $\mathrm{OH}$ exposure (and $\mathrm{O}_{3}$ concentration) and BES reaction as described by the fractional increase in AMS $m / z$ 44. These BES experiments were used to confirm the stability of the $\mathrm{O}_{3}$ concentration/OH exposure relationship, not to perform a priori estimation of the $\mathrm{OH}$ exposure. Such an estimate would be complicated by factors such as instrument-to-instrument differences in fragmentation patterns, differences in the kinetics between gas-phase and heterogeneous reactions, etc. Control experiments indicated negligible reactivity with $\mathrm{O}_{3}$ at TPOT concentrations (40 to 1100 ppbv) (see Fig. S2). OH exposures calculated from the MEK calibrations were reproducible to within $\sim 30 \%$.

The temperature within the reaction zone was monitored by thermocouple mounted on the inner wall of the lamp housing, thereby approximating the closest surface to the lamp encountered by the ambient aerosol. During WACS 2010, the lamp subjected the sampled air to a temperature increase of $\sim 4{ }^{\circ} \mathrm{C}$ relative to the indoor temperature at the sampling enclosure. However, it is possible that the aerosol does not reach room temperature before entering the TPOT, and that the heating is instead described by the difference between outdoor and TPOT temperatures. The time series of this relationship is plotted in the Supplement (Fig. S1) and yields a mean temperature difference of $10.4 \pm 2.1^{\circ} \mathrm{C}$.

\subsection{Aerosol mass spectrometer}

The Aerodyne time-of-flight aerosol mass spectrometer (CToF-AMS, Aerodyne Research, Inc., Billerica, MA, USA) provides the non-refractory composition of particles with vacuum aerodynamic diameter between approximately 60 and $600 \mathrm{~nm}$ (Drewnick et al., 2005). Instrument characteristics and operating/analysis procedures are described in detail in the literature (e.g. Jayne et al., 2000; Allan et al., 2003; Canagaratna et al., 2007). Particles are continuously sampled from atmosphere through a $100 \mu \mathrm{m}$ critical orifice $\left(\sim 100 \mathrm{~cm}^{3} \mathrm{~min}^{-1}\right)$ into an aerodynamic lens $(\sim 2$ torr), which focuses the particles into a narrow beam. The particles impact on a resistively-heated tungsten surface $\left(600^{\circ} \mathrm{C}\right.$, $10^{-7}$ torr), where they flash vaporize. The resulting gas is ionized by electron impact $(70 \mathrm{eV})$ and the ions are detected by a time-of-flight mass spectrometer (Tofwerk AG, Thun, Switzerland). The AMS also has particle sizing capabilities, but these were not utilized during the present study due to mechanical problems. Mass spectra were recorded with 1 min time resolution.

During normal operation, the particle beam is alternately blocked, yielding the instrument background, and unblocked. The difference between these two measurements is the mass spectrum of the sampled particles, together with signal from the major gases in air (primarily $\mathrm{N}_{2}, \mathrm{O}_{2}, \mathrm{H}_{2} \mathrm{O}, \mathrm{Ar}$, and $\mathrm{CO}_{2}$ ). Contributions from these gases, including fragment and isotopic ions, are removed from the particle spectra through the
ToF-AMS Toolkit v1.51 data analysis package (D. Sueper, University of Colorado-Boulder, Boulder, CO, USA) for Igor Pro v6.22A (Wavemetrics, Inc., Lake Oswego, OR, USA) based on the mass spectral fragmentation analysis algorithm developed by Allan et al. (2003). These algorithms are also used to quantitatively separate organic ion signals from other species. Gaseous fragmentation patterns were characterized using regular filter measurements to zero the particle signal. A collection efficiency of 0.5 is assumed throughout the AMS transmission window. However, the analysis herein utilizes normalized values or ratios and is therefore unaffected by this assumption.

\subsection{Positive matrix factorization}

The AMS organic mass spectral time series was analyzed using positive matrix factorization (PMF) (Paatero and Tapper, 1994; Paatero 1997). PMF represents the AMS time series as a linear combination of static factor profiles and their time-dependent intensities according to the matrix equation $\mathbf{X}=\mathbf{G F}+\mathbf{E}$, where $\mathbf{X}$ is the data matrix ( $i$ time points $\mathbf{x}$ $j \mathrm{~m} / z$ ), the $\mathbf{G}$ matrix contains the factor time series matrix ( $i$ time points $\mathrm{x} p$ factors), the $\mathbf{F}$ matrix contains the factor mass spectra ( $p$ factors vs. $j \mathrm{~m} / z$ ) and $\mathbf{E}$ is the residual matrix ( $i$ time points $\mathrm{x} j \mathrm{~m} / z$ ). PMF requires as inputs the AMS mass spectral time series and associated uncertainties, which are calculated according to Allan et al. (2003). The first application of PMF to AMS datasets was conducted by Lanz et al. (2007), and many other studies have followed.

For the TPOT data during WACS 2010, the AMS dataset $\mathbf{X}$ consists of 20778 time points (i.e. 1-min mass spectra) and $270 \mathrm{~m} / \mathrm{z}$. A minimum error corresponding to measurement of a single ion was applied to the dataset and $\mathrm{m} / \mathrm{z}$ assumed in AMS data analysis procedures to be proportional to $m / z, 44$ were downweighted as described in Ulbrich et al. (2009). No further downweighting was applied to the dataset.

PMF allows the user to determine the number of factors in the output solution; here solutions containing 1 to 12 factors were investigated. Matrix rotations were explored by varying the fPeak parameter from -2 to 2 . The selected solution (see Sect. 3.3) was a 5-factor solution at fPeak $=-0.5$. The value of the object function $Q$, calculated as the sum of the squares of the uncertainty-scaled residuals, was 1.13 times the theoretically-expected value. The average residual, calculated as the mean of $\mid$ residual|/signal, was 0.083 . 5factor solutions with $f P e a k$ values between -0.5 and 0 were not convergent using the standard criteria, and the negative fPeak solutions provided more clearly distinguished factors than the positive fPeak ones. Convergence could be achieved for fPeak values between -0.5 and 0 only by significantly relaxing the convergence criteria, which yielded solutions with significantly higher $Q$-values; these solutions were therefore rejected. Each factor in the 5 -factor solution could be interpreted meaningfully, making it preferable to lower-order solutions. Higher order solutions provided uninterpretable 
factors and/or split/mixed factors, which frequently indicate an excessive number of factors (Ulbrich et al., 2009). The possibility of local minima in the PMF solution was explored by initiating the PMF algorithm from 150 different random starting points ("seeds"); no solutions with significant differences from the selected solution were found.

\section{Results and discussion}

The Whistler site is in a forested region with strong monoterpene emissions. A summary of the major results from the WACS 2010 campaign is provided elsewhere (Macdonald et al., 2012). During the periods of TPOT sampling, the aerosol can mostly be classified as biogenic SOA resulting from gas-phase oxidation of monoterpenes. The primary exception to this classification occurred near the end of the campaign (26 to 27 July), when the site was influenced by transported aerosol from regional forest fires. Strong diurnal cycles of organic mass, biogenic VOC emissions and oxidizing species are observed, which can be attributed to both upslope/downslope flow and local chemical reactions.

As discussed in Sect. 2.2, aerosol passing through the TPOT is subjected to one of four conditions: (1) unreacted ambient aerosol (ambient condition, "Amb"); (2) exposure to $\mathrm{O}_{3}$ (ambient $+\mathrm{O}_{3}$ condition, " $\mathrm{AmbO}_{3}$ "); (3) exposure to UV light (ambient + UV condition, "AmbUV"); and (4) exposure to $\mathrm{O}_{3}$ and light, resulting in exposure to $\mathrm{OH}$ radicals (ambient + UV + OH condition, "AmbUVOH"). Control experiments comparing conditions (1) and (2) to determine the effects of $\mathrm{O}_{3}$ exposure showed no changes above detection limit to either the total organic mass or individual $\mathrm{m} / \mathrm{z}$ within the spectrum. A sample control experiment of this type is shown in the Supplement (Fig. S2) and the $\mathrm{R}^{2}$ between the spectra is 0.9995 . Therefore, from this point we will treat conditions (1) and (2) as equivalent and refer to both as the "Amb" condition. For the AmbUV condition, we cannot distinguish the effects of volatilization and irradiation by $254 \mathrm{~nm}$ light. We further note that although only a $4{ }^{\circ} \mathrm{C}$ temperature increase was measured for the AmbUV condition, some larger local increases in temperature may occur within the TPOT, especially near the quartz tube. Effects of volatilization/UV exposure and $\mathrm{OH}$ oxidation on the mass spectra are treated separately below in Sects. 3.1 and 3.2. Because repeated perturbation of the ambient aerosol by the TPOT forces mass spectral variability based on particle volatility/UV reactivity and $\mathrm{OH}$ reactivity, factor analysis describes the particle composition in terms of these properties. This is illustrated via PMF analysis of the TPOT AMS data in Sect. 3.3. The duration of Amb, AmbUV, and AmbUVOH periods varies throughout the study in response to changes in selected $\mathrm{OH}$ exposure and observed ambient aerosol composition. Listings of the averaging periods used are presented in the supplement (Table S1 for Amb, Table S2 for AmbUV and AmbUVOH in the Supplement).

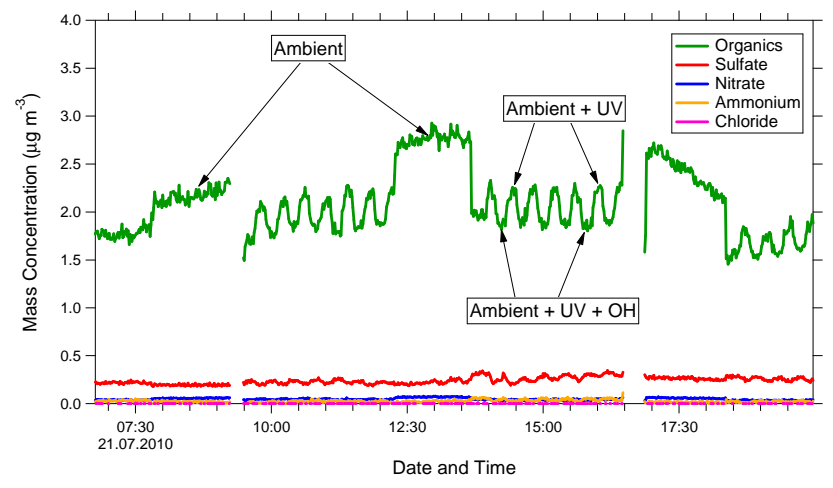

Fig. 2. Sample time series for TPOT AMS data, showing ambient, ambient $+\mathrm{UV}$, and ambient $+\mathrm{UV}+\mathrm{OH}$ conditions.

\subsection{UV exposure}

Figure 2 shows a sample time series of TPOT data, with ambient ("Amb"), ambient + 254 nm UV light ("AmbUV"), and ambient + UV light + OH ("AmbUVOH") conditions labelled. The figure shows a decrease in organic mass on the order of $15 \%$ between the Amb and AmbUV conditions. There are two possible explanations for this mass loss: (1) volatilization of semivolatile organics due to heating induced by the UV lamp; or (2) photolysis of OA species such as peroxides. Although the sampled aerosol is diluted by a humidified $\mathrm{N}_{2} / \mathrm{O}_{2}$ flow within the TPOT system, this dilution takes place before the particles are split into Amb and AmbUV pathways and therefore does not contribute to the observed mass loss. Wall loss experiments were conducted in the reaction zone with the UV lamp on using size-selected bis(2ethylhexyl) sebacate ("BES", $\mathrm{C}_{26} \mathrm{H}_{50} \mathrm{O}_{4}$ ) particles. These experiments showed approximately $100 \%$ transmission for 100 to $300 \mathrm{~nm}$ particles, and approximately $90 \%$ transmission for $50 \mathrm{~nm}$ particles. Losses through the 3-way switching valve were not calculated, however here the pathways taken by the $\mathrm{Amb}$ and AmbUV pathways are identical. It is therefore extremely unlikely that particle losses significantly contribute to the observed mass loss. Finally, we note that the comparison of Amb and AmbUV periods requires interpolation of the Amb condition over a 3 to 4 hour time interval (see Tables S1 and S2 in the Supplement). While this introduces some scatter into the Amb/AmbUV comparison, because the sampling site is influenced primarily by daily temperature/boundary layer cycles and major changes in weather/air mass origin (as opposed to local sources), the interpolation is not expected to bias the comparison.

The relative effects of photolysis and volatilization on OA mass loss between Amb and AmbUV conditions cannot be deconvolved in the current dataset. Note that the AmbUV condition represents an approximate temperature increase of only $\sim 4{ }^{\circ} \mathrm{C}$ (TPOT vs. indoor air temperature) to $\sim 10^{\circ} \mathrm{C}$ (TPOT vs. outdoor air temperature). If this mass loss was caused by TPOT heating, it would indicate that the particles 

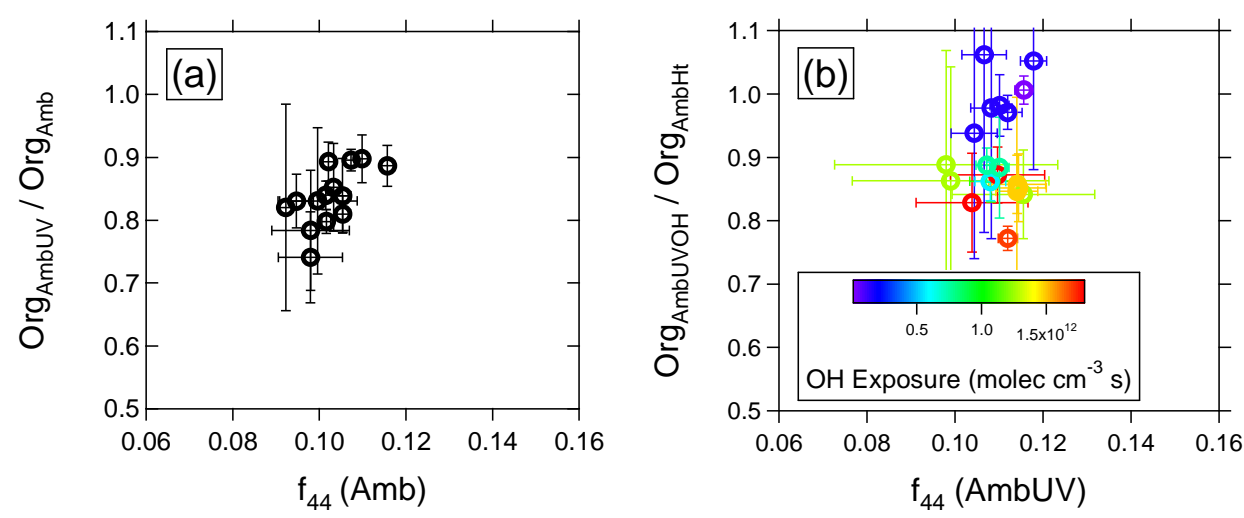

Fig. 3. (a) Fraction of organic mass remaining at the AmbUV condition as a function of $f_{44}$. Volatilization occurs as a result of a $4{ }^{\circ} \mathrm{C}$ increase in temperature. (b) Organic mass decrease as a function of $f_{44}$ and $\mathrm{OH}$ exposure. Note that axes do not go to zero in either figure.

are quite volatile. Conversely, if the mass loss were due to photolysis, it would indicate a large fraction of photoreactive species such as peroxides. Figure $3 a$ shows the fraction of mass lost as a function of $f_{44}$ over the entire campaign, where $f_{44}$ is defined as the fraction of organic mass occurring at $m / z$ 44. (Averaging periods for the data points in this and similar figures are reported in Table S1.) For each point in Fig. 3a, the $\operatorname{Org}_{\mathrm{Amb}}$ is calculated as the mean of a single ambient measurement period, as denoted by one of the labelled periods in Fig. 2. The corresponding $\operatorname{Org}_{\text {AmbUV }}$ data is drawn from the average of the two nearest flanking AmbUV periods $(12 \mathrm{~min})$. The signal at $\mathrm{m} / \mathrm{z} 44$ is dominated by the $\mathrm{CO}_{2}^{+}$ion, which in the AMS is frequently observed from organic acids (e.g. Duplissy et al., 2011). $f_{44}$ can be used to estimate the molecular O:C ratio (Aiken et al., 2008). Over the entire study, the AmbUV condition causes a loss of 10 to $25 \%$ of the organic signal. As shown in Fig. 3a, the fraction of organics lost decreases with increasing $f_{44}$, suggesting that particle volatility and/or photolysis is inversely related to oxygenation. This trend with volatility is consistent with previous studies (e.g. Huffman et al., 2009). There is no dependence of $\mathrm{Org}_{\mathrm{AmbUV}} / \mathrm{Org}_{\mathrm{Amb}}$ on the temperature difference between the TPOT and outdoor air. While the correlation shows significant scatter, the trend is evident. Note also that some volatilized OA may recondense on the particles, so volatility effects on the mass loss in Fig. 3a will be somewhat suppressed. Sample mass spectra comparing the Amb and AmbUV conditions are shown in Fig. S3 in the Supplement.

\subsection{OH oxidation}

Exposure of aerosol to $\mathrm{OH}$ radicals (i.e. the AmbUVOH) condition causes a further decrease in organic mass relative to $\operatorname{Org}_{\text {AmbuV }}$ (see Fig. 2). As shown in Fig. 3b, the magnitude of this decrease depends primarily on $\mathrm{OH}$ exposure, with the extent of oxidation of the unprocessed particle (as represented by $f_{44}$ ) having little effect. (Averaging periods for this and similar figures are given in Table S2.) A crucial feature of this plot is that an organic mass increase beyond experimental uncertainties is not observed for any $\mathrm{OH}$ exposure. This suggests that chemistry in the TPOT is dominated by heterogeneous reactions and/or gas-phase reactions of semivolatile species partitioning from the particle phase, and that SOA formation is not significant. This is consistent with the flowtube intercomparison study of Lambe et al. (2011a), which showed the SOA yield from a system decreases with an increasing ratio of wall surface area to volume. Peak monoterpene concentrations during the period of TPOT sampling were on the order of $0.5 \mathrm{ppbv}$ (Macdonald et al., 2012); at these levels, significant TPOT SOA formation is not expected (Lambe et al., 2011a). SOA yields also decrease with decreasing VOC concentrations; for a relatively pristine site such as Whistler, TPOT SOA production is negligible.

As shown in Fig. 2, TPOT conditions also slightly affect the inorganic species. Notably, sulfate and ammonium increase for the AmbUVOH condition, while nitrate decreases. The increase in sulfate is likely due to oxidation of gas-phase $\mathrm{SO}_{2}$ to $\mathrm{H}_{2} \mathrm{SO}_{4}$. This $\mathrm{H}_{2} \mathrm{SO}_{4}$ is then rapidly neutralized by ammonium, resulting in a corresponding increase of particulate ammonium. The decrease in nitrate may be due either to consumption of organonitrates, whose major mass fragments occur at the same $\mathrm{m} / \mathrm{z}$ as inorganic nitrate, or to reaction of $\mathrm{HNO}_{3}$ with $\mathrm{OH}$.

Figure 4 describes the changes in the AMS mass spectra due to volatilization and $\mathrm{OH}$ oxidation using the framework developed by $\mathrm{Ng}$ et al. (2010). Ambient SOA typically falls within the triangle denoted by the solid lines in the figure, with more aged (and typically less volatile) SOA lying in the upper left. PMF analyses of AMS spectra often resolve two SOA-related factors, termed low-volatility and semi-volatile oxygenated organic aerosol (LV-OOA and SVOOA), which respectively fall in the upper left and lower sections of this triangle. As shown in the figure, the ambient particles begin in the SV-OOA region of the triangle. Volatilization (AmbUV condition) moves them only 


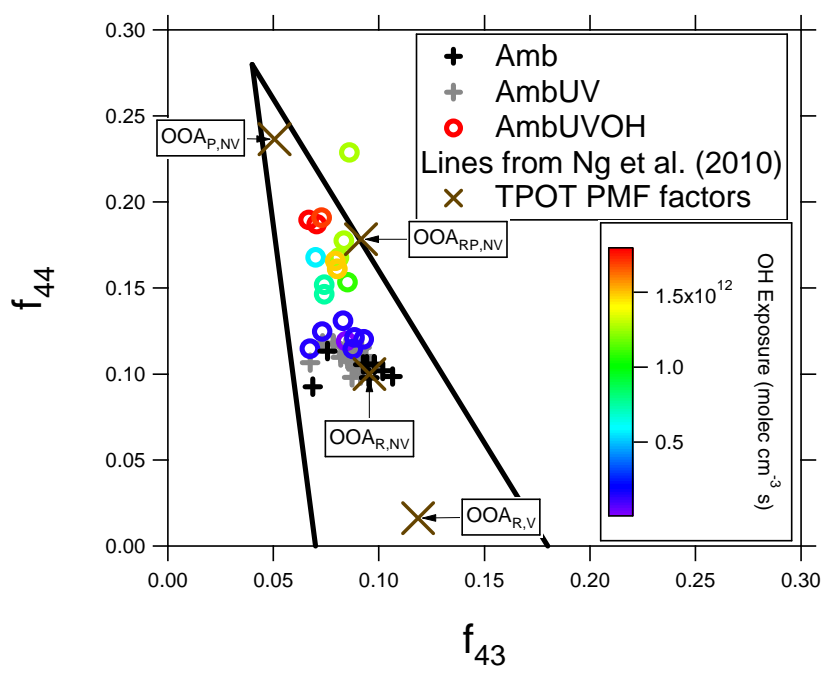

Fig. 4. Aerosol composition described in terms of the fraction of organic mass at $\mathrm{m} / z, 44$ and $43\left(f_{44}\right.$ and $\left.f_{43}\right)$. Data points are colored by $\mathrm{OH}$ exposure, and lines denote the limits of PMF OOA factors resolved from ambient data ( $\mathrm{Ng}$ et al., 2010). Values for TPOT PMF factors are also shown.

slightly upwards and to the left. However, a strong effect is seen from $\mathrm{OH}$ oxidation. At the lowest $\mathrm{OH}$ exposure levels $\left(\sim 1.5 \times 10^{11}\right.$ molec $\left.\mathrm{cm}^{-3} \mathrm{~s}\right)$, only a slight movement towards the upper left is observed. However, the highest $\mathrm{OH}$ exposures $\left(\sim 1.5 \times 10^{12}\right.$ molec $\left.\mathrm{cm}^{-3} \mathrm{~s}\right)$ move the composition well into the LV-OOA region of the triangle. These $\mathrm{OH}$ exposures correspond to approximately 0.85 and 10 day-equivalents of atmospheric aging, respectively, assuming a 24-h mean $\mathrm{OH}$ concentration of $2 \times 10^{6}$ molec $\mathrm{cm}^{-3}$. Note, however, that significant aging takes place on shorter timescales; an $\mathrm{OH}$ ex-

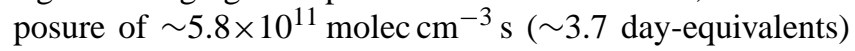
already causes movement into the LV-OOA region.

While the framework utilized in Fig. 4 provides a simple overview of the aging process, additional information is available from consideration of the entire mass spectrum. Fig. 5 shows the effects of low and high $\mathrm{OH}$ exposures on the intensities of all organic $\mathrm{m} / \mathrm{z}$ up to $\mathrm{m} / \mathrm{z}, 125$. Changes in the mass spectra are plotted as the ratio of spectra obtained under the AmbUVOH condition to the AmbUV condition (the AmbUV and AmbUVOH spectra are plotted independently in Fig. S4 in the Supplement). Spectra are not normalized, so a value of 1 indicates no change in the mass measured at that $m / z$, while values $>1$ or $<1$ indicate mass increases or decreases, respectively. The figures show decreases at all $\mathrm{m} / \mathrm{z}$ except for $\mathrm{m} / \mathrm{z} 44,45$, and $\mathrm{m} / \mathrm{z}$ dependent on 44 . (In the AMS data processing algorithm, the organic signal at $\mathrm{m} / \mathrm{z} 16$ through 21 and 28 are assumed to be in constant proportion to $m / z 44$ (Allan et al., 2003; Aiken et al., 2008). The apparent increases at some higher $\mathrm{m} / \mathrm{z}$ for the low $\mathrm{OH}$ condition occur at $\mathrm{m} / \mathrm{z}$ having too low signal for the apparent increases to be reliable. The lone exception occurs at $m / z$ 45. Approx-

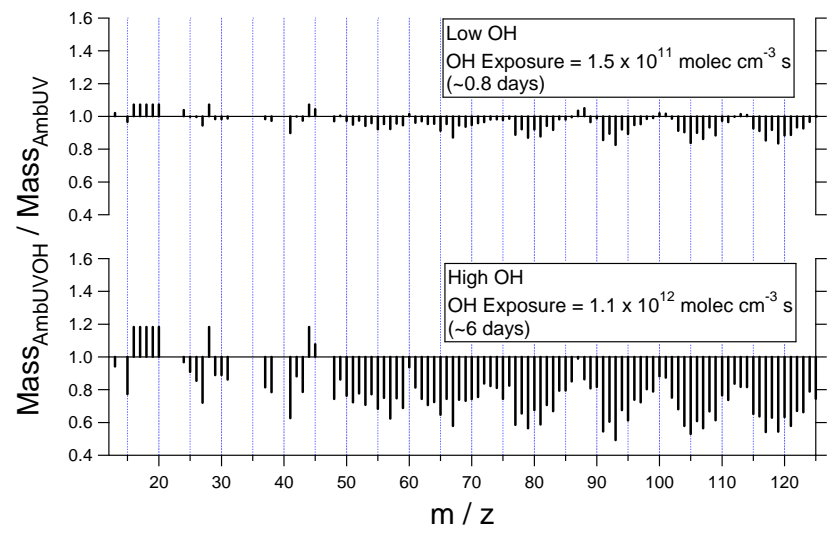

Fig. 5. Mass spectral changes due to $\mathrm{OH}$ oxidation for low and high $\mathrm{OH}$ exposures. Spectral changes are plotted as the ratio of spectra obtained at the AmbUVOH condition to the AmbUV condition. Individual spectra used to create this plot are shown in the Supplement.

imately $10 \%$ of the signal at this ion results from the $\mathrm{CO}_{2}^{+}$ isotope, and the rest is probably dominated by the $\mathrm{HCO}_{2}^{+}$ion, which would also suggest the formation of organic acids (see Fig. S5).

While decreased mass due to $\mathrm{OH}$ oxidation is evident throughout the spectra shown in Fig. 5, the fractional decrease varies significantly by $m / z$. For example, at the high $\mathrm{OH}$ exposure, $\mathrm{m} / \mathrm{z} 43$ decreases by $37 \%$, while $\mathrm{m} / \mathrm{z} 105 \mathrm{de}-$ creases by $47 \%$. Generally, the fractional decrease is larger for fragments at higher $\mathrm{m} / \mathrm{z}$ and for fragments characteristic of hydrocarbons or slightly oxygenated hydrocarbons. The change in mass for selected fragments $(\mathrm{m} / \mathrm{z} 43,44,55$, and 91 ) and total organic mass is shown as a function of $\mathrm{OH}$ exposure in Fig. 6. The trends shown in Fig. 5 are also evident in this figure, with for example $m / z, 91$ showing a stronger decrease than $\mathrm{m} / \mathrm{z}$ 43. However, Fig. 6 also provides additional insight into the rate of heterogeneous oxidation. The rate of mass decrease slows considerably after $\sim 3$ day-equivalents of oxidation ( $\mathrm{OH}$ exposures $\sim 6.9 \times 10^{11} \mathrm{molec} \mathrm{cm}^{-3} \mathrm{~s}$ ), as do the changes in composition.

Fitting the $m / \mathrm{z} 44$ production to the function $y=1+a\left(1-e^{-k x}\right)$ yields a kinetic rate constant of $3.0 \times 10^{-12} \mathrm{~cm}^{3}$ molec $^{-1} \mathrm{~s}^{-1}$. Rate constants for the reaction of other $\mathrm{m} / \mathrm{z}$, as well as for PMF factors (see Sect. 3.3), are given in Table 1. While significant uncertainties exist because of the scarcity of TPOT data at low $\mathrm{OH}$ exposures, this value indicates considerably faster $\mathrm{m} / \mathrm{z}, 44$ production than that observed for bis(2-ethylhexyl) sebacate $\left(\mathrm{C}_{26} \mathrm{H}_{50} \mathrm{O}_{4}\right)$, a long-chain saturated hydrocarbon with two ester groups $\left(k=5.58 \times 10^{-13} \mathrm{~cm}^{3} \mathrm{molec}^{-1} \mathrm{~s}^{-1}\right.$, George et al., 2007). The TPOT $m / z 44$ production rate is quite similar to the production of primary products from BES oxidation $\left(k=2.8 \times 10^{-12} \mathrm{~cm}^{3} \mathrm{molec}^{-1} \mathrm{~s}^{-1}\right.$ ), suggesting that $\mathrm{m} / \mathrm{z} 44$ (characteristic of carboxylic acids) is a primary product of the ambient aerosol oxidation, rather than requiring multiple 


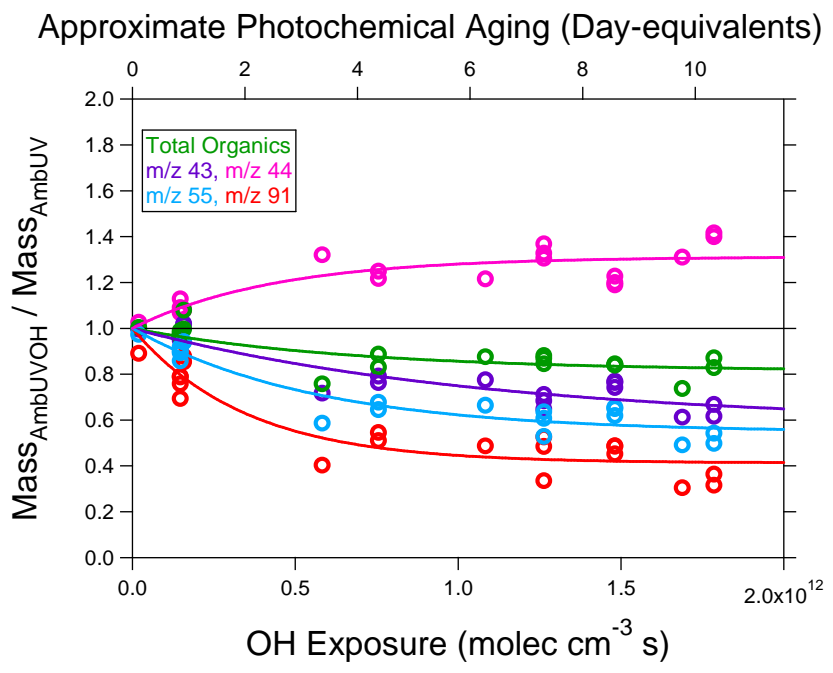

Fig. 6. Change in mass of selected organic $\mathrm{m} / \mathrm{z}(43,44,55$, and 91) and total organic mass as a function of $\mathrm{OH}$ exposure. Photochemical age is estimated assuming a mean $\mathrm{OH}$ concentration of $2 \times 10^{6}$ molec $\mathrm{cm}^{-3}$. Data is fitted to $y=1+a\left(1-e^{-k x}\right)$.

steps to be produced. This is also consistent with the lack of increase at any $\mathrm{m} / \mathrm{z}$ other than 44 in Fig. 6. However, we cannot rule out the possibility that an increase in an ion due to $\mathrm{OH}$ oxidation may be offset by a corresponding decrease by a different ion at the same nominal $\mathrm{m} / \mathrm{z}$.

Oxidation of biogenic SOA in this study has some similarities to heterogeneous $\mathrm{OH}$ oxidation of urban aerosol. For the urban aerosol, $\mathrm{m} / \mathrm{z} 44$ enhancement of up to $20 \%$ was observed (George et al., 2008), while a $25 \%$ increase was observed for biogenic SOA (see Fig. 6). For both aerosol types, production of $\mathrm{m} / \mathrm{z} 44$ occurs relatively rapidly, with most of the production occurring in less than $\sim 3$ day-equivalents of $\mathrm{OH}$ exposure. This suggests a similar rate for fragmentation reactions. Here a fragmentation reaction is defined as a reaction adding oxygen with a net carbon loss, while a functionalization reaction adds oxygen with no net carbon loss (Kroll et al., 2009). However, the total biogenic SOA mass decreased even at low exposures, quickly reaching its maximum decrease of $\sim 15 \%$ in less than $\sim 3$ day-equivalents of $\mathrm{OH}$ exposure. In contrast, decrease in urban OA mass was observed until $\sim 8$ day-equivalents of exposure, although a similar OA decrease $(\sim 20 \%)$ was observed for the highest exposures (George et al., 2008). The similar OA loss at high exposures suggests similar functionalization/fragmentation branching ratios for the two aerosol types. However, the lower $\mathrm{OH}$ exposures needed to induce OA loss for the biogenic aerosol indicates that fewer fragmentation reactions are required, perhaps because the biogenic SOA has a product distribution weighted towards more volatile species.

Further insight into the mechanistic changes to biogenic SOA associated with heterogeneous $\mathrm{OH}$ oxidation can be used by investigation of the location of the OA in the Van
Table 1. Kinetic rate constants for total organics, selected $m / z$, and $\mathrm{PMF}$ factors with $\mathrm{OH}$

\begin{tabular}{ll}
\hline Reacted species & $\mathrm{K}_{\mathrm{OH}}\left(\mathrm{cm}^{3} \mathrm{molec}^{-1} \mathrm{~s}^{-1}\right)$ \\
\hline Organics & $4.35 \times 10^{-12}$ \\
$m / z 43$ & $9.18 \times 10^{-13}$ \\
$m / z 55$ & $1.78 \times 10^{-12}$ \\
$m / z 57$ & $1.83 \times 10^{-12}$ \\
$m / z, 91$ & $2.88 \times 10^{-12}$ \\
$m / z, 105$ & $3.40 \times 10^{-12}$ \\
OOA $_{\mathrm{R}, \mathrm{V}}$ & $3.26 \times 10^{-12}$ \\
OOA $_{\mathrm{R}, \mathrm{NV}}$ & $1.92 \times 10^{-11}$ \\
\hline Produced Species & $\mathrm{K}_{\mathrm{OH}}\left(\mathrm{cm}^{3} \mathrm{molec}^{-1} \mathrm{~s}^{-1}\right)$ \\
\hline$m / z 44$ & $2.29 \times 10^{-12}$ \\
OOA, $\mathrm{NV}$ & $4.35 \times 10^{-12}$ \\
\hline
\end{tabular}

Krevelen space, that is the molecular $\mathrm{H}: \mathrm{C}$ ratio as a function of the O:C ratio (Heald et al., 2010). Because the AMS instrument used for the current study is capable only of unit mass resolution measurements, the $\mathrm{O}: \mathrm{C}$ ratio is estimated using the parameterization of Aiken et al. (2008) based on the fraction of organic mass contained at $\mathrm{m} / \mathrm{z}$ 44. The $\mathrm{H}: \mathrm{C}$ ratio is estimated using the parameterization of $\mathrm{Ng}$ et al. (2011a), which is based on the organic mass fractions at $\mathrm{m} / \mathrm{z}$ 43. The $\mathrm{Ng}$ et al. (2011a) parameterization has been evaluated for SOA only, and only for OA where $0.05<f_{43}<0.25$ and $f_{44}>0.06$. The $f_{43}$ and $f_{44}$ conditions are satisfied for the current dataset $\left(f_{43}\right.$ minimum/maximum $=0.067 / 0.093 ; f_{44}$ $\operatorname{minimum} /$ maximum $=0.10 / 0.23$ ). The organic aerosol composition during periods of TPOT operation was likely dominated by SOA (Macdonald et al., 2012) with the exception of 26 to 27 July, when the site was influenced by local biomass burning emissions.

Figure 7a shows the Van Krevelen plot (estimated molecular $\mathrm{H}: \mathrm{C}$ vs. O:C ratios) for the AmbUV and AmbUVOH conditions (open and closed symbols, respectively), with the data points colored by $\mathrm{OH}$ exposure. Corresponding AmbUV and AmbUVOH conditions are connected by a line, the slope of which is plotted in Fig. $7 \mathrm{~b}$ as a function of the $\mathrm{OH}$ exposure. Points that are possibly influenced by the 26 to 27 July biomass burning plume are labeled (and discussed in Sect. 3.3). Similar to Fig. 6, most chemical changes to the aerosol already occur for $\mathrm{OH}$ exposures below $6.9 \times 10^{11}$ molec $\mathrm{cm}^{-3} \mathrm{~s}(\sim 3$ day-equivalents of oxidation). The slope of the Van Krevelen plot has previously been interpreted in terms of changes in organic functionality (e.g. Heald et al., 2010; Ng et al., 2011a). In the present study, Van Krevelen slopes of approximately -0.1 and -0.2 are observed for low and high $\mathrm{OH}$ exposures, respectively. The combination of these slopes with the observed lack of increase in any $\mathrm{m} / \mathrm{z}$ other than $\mathrm{m} / \mathrm{z} 44$ (see Figs. 5 and 6) suggests the changes in the aerosol 

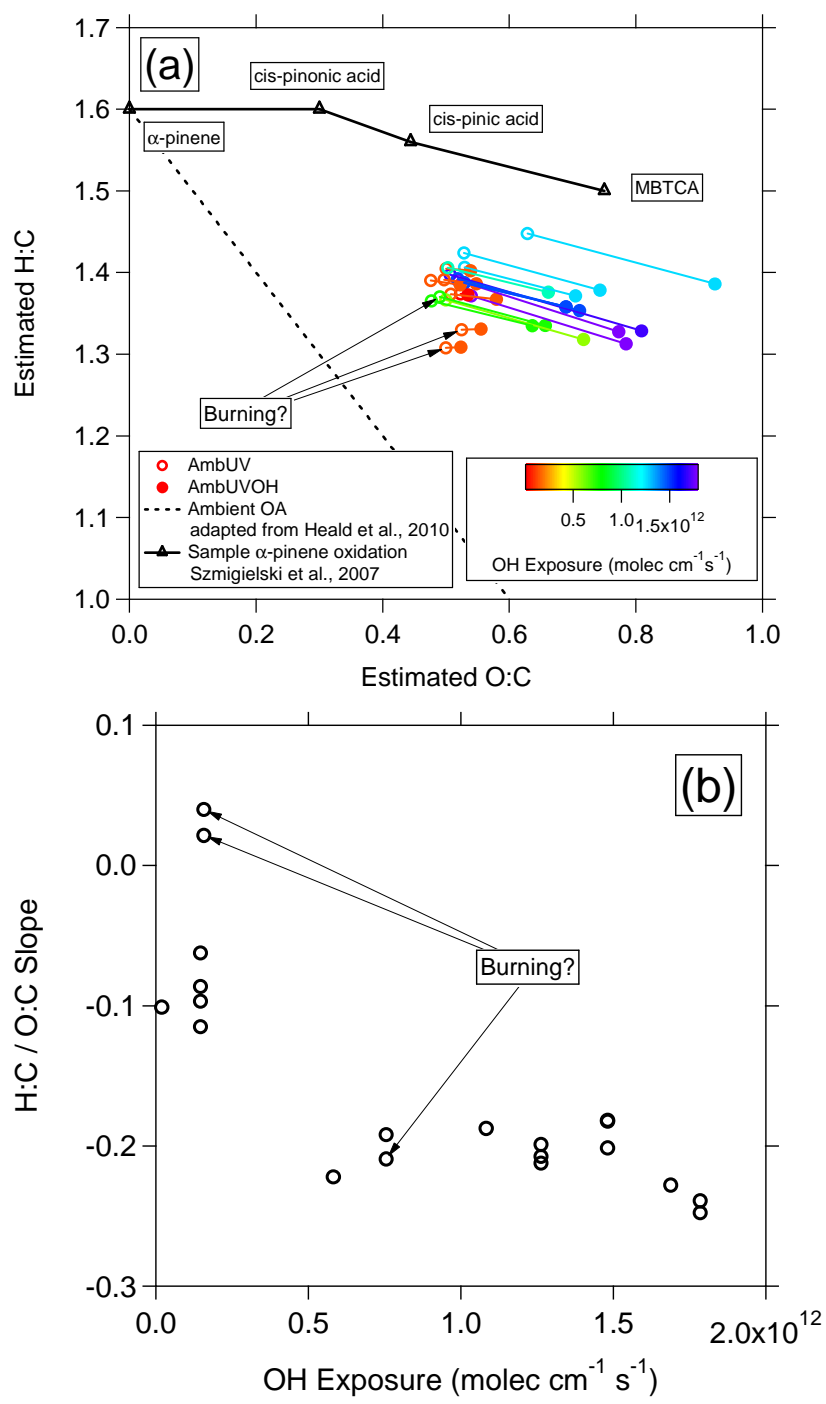

Fig. 7. (a) Estimated Van Krevelen plot for AmbUV and AmbUVOH conditions, colored by $\mathrm{OH}$ exposure. $\mathrm{H}: \mathrm{C}$ and $\mathrm{O}: \mathrm{C}$ ratios are estimated from the SOA parameterization of $\mathrm{Ng}$ et al. (2011). Dashed line has a slope of -1 , which was observed in ambient OA by Heald et al. (2010), but begins at begins at $\mathrm{H}: \mathrm{C}=1.6, \mathrm{O}: \mathrm{C}=0$ to reflect the probable dominance of terpene precursors. An example of an $\alpha$-pinene oxidation pathway is also shown (Szmigielski et al., 2007). (b) Van Krevelen slopes from Fig. 7a as a function of $\mathrm{OH}$ exposure.

are driven by significant fragmentation coupled with formation of $\mathrm{COOH}$ groups. Given the $\sim 10 \%$ uncertainty in the $\mathrm{H}: \mathrm{C}$ parameterization ( $\mathrm{Ng}$ et al., 2011a) and the assumptions discussed above, the obtained Van Krevelen slopes are consistent with known $\alpha$-pinene oxidation mechanisms. For example, one pathway for the oxidation of $\alpha$-pinene $\left(\mathrm{C}_{10} \mathrm{H}_{16}\right)$ proceeds to the 1 st-generation product cis-pinonic acid $\left(\mathrm{C}_{10} \mathrm{H}_{16} \mathrm{O}_{3}\right.$, slope $\left.=0\right)$, then to cis-pinic acid $\left(\mathrm{C}_{9} \mathrm{H}_{14} \mathrm{O}_{4}\right.$ slope $=-0.3$, while subsequent oxidation to 3-methyl-1,2,3butanetricarboxylic acid (MBTCA) follows a slope of -0.2
(Szmigielski et al., 2007). This oxidation pathway is plotted in Fig. 7a together with the TPOT data, and the two processes have similar slopes.

\subsection{PMF analysis}

Positive matrix factorization was conducted on the TPOT AMS organic mass spectra. The analyzed dataset includes the Amb, AmbUV, and AmbUVOH conditions. When applied to an AMS mass spectral time series, PMF uses temporal correlations between $\mathrm{m} / \mathrm{z}$ to resolve factors. Temporal variability in the mass spectrum is therefore required for PMF analysis. In conventional AMS datasets (i.e. direct ambient sampling), this variability is governed by factors such as transport, source locations, atmospheric reactions, etc. In contrast, mass spectral variability in the TPOT dataset is governed by volatilization and $\mathrm{OH}$ oxidation. Therefore, separation of factors in the TPOT PMF is governed by properties of particle components such as volatility, reactivity, and reaction product formation. This provides a useful framework for discussing particle properties and aging that would not otherwise be accessible.

A 5-factor solution was selected for the TPOT PMF. This solution provides a set of factors that can each be meaningfully interpreted. Higher-order solutions include "split" factors, which can indicate an excessive number of factors (Ulbrich et al., 2009) and/or factors that cannot be meaningfully interpreted from the available data. An excerpt of the factor time series from the 5-factor solution for a typical day is shown in Fig. 8a, while the time series from a short period influenced by a local biomass burning plume at the end of the study is shown in Fig. 8b. Only excerpts of the entire time series are shown to make visible the effects of TPOT conditions, and a sample of the Amb, AmbUV, and AmbUVOH conditions are shown as shaded regions. Residuals corresponding to the excerpted time series, and mass spectral residuals for the entire campaign are shown in Fig. S6 in the Supplement. The five factors include a biomass burning organic aerosol (BBOA) factor and four oxygenated organic aerosol (OOA) factors. In addition to the PMF factors, Fig. 8 shows the time series of acetonitrile (measured by a PTRMS) and the AMS signal at $m / z 39$, which is related both to potassium and organics.

Figure $8 \mathrm{~b}$ shows a strong increase in the BBOA factor coinciding with arrival of the plume at the sampling site. In addition to the AMS BBOA factor, the effects of the plume could be observed visually and by smell, through a spike in gas-phase acetonitrile and AMS m/z 39 and connected by meteorology to known local forest fires (Macdonald et al., 2012). Because of the short temporal duration of biomass burning influences at the site, it is likely that PMF is unable to retrieve a "pure" BBOA factor. This is suggested by high residuals at $m / z 60$, during the biomass burning period. This $\mathrm{m} / \mathrm{z}$ is a characteristic fragment of cellulose pyrolysis products such as levoglucosan. The organic mass fraction 

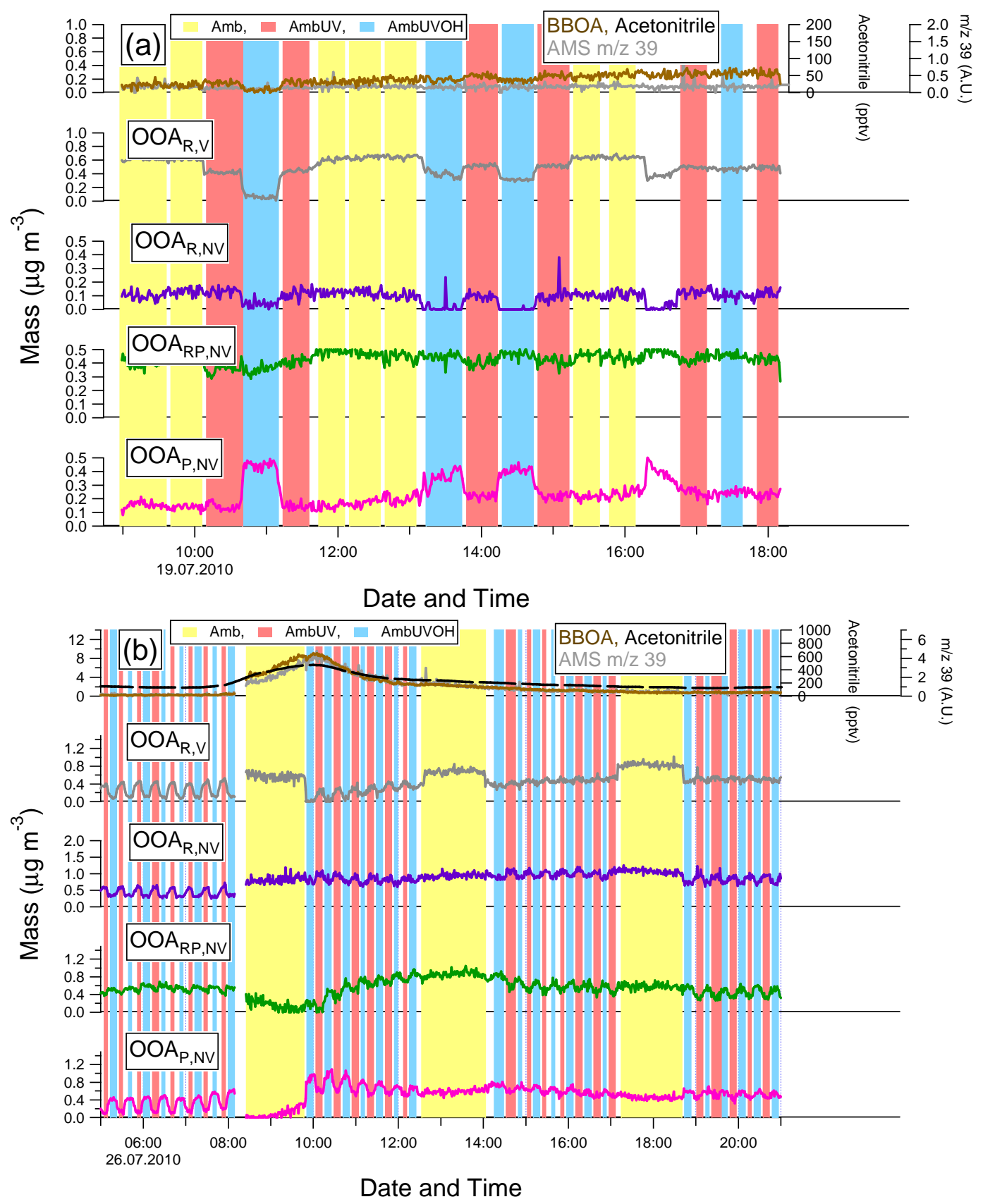

Fig. 8. Excerpted periods from the factor time series from the 5-factor solution to the TPOT PMF dataset, showing a typical day (a) and a biomass burning plume (b). Amb, AmbUV, and AmbUVOH periods are indicated by colored shading. PMF factors are shown as colored traces. PTR-MS measurement of acetonitrile (black) and AMS estimate of potassium (gray) are also shown.

at $m / z 60\left(f_{60}\right)$ is typically elevated above background levels during periods of biomass burning influence (Cubison et al., 2011). In the present study, $f_{60}$ reaches a maximum of $0.72 \%$ during the biomass burning periods (compared to background values of $0.2 \pm 0.05 \%$ ), while the $f_{60}$ value for the BBOA factor itself is only $0.51 \%$, indicating that the BBOA factor does not fully represent the variability of this important biomass burning tracer. Note further that even dur- ing the burning period, the BBOA factor never accounts for more than $80 \%$ of the total OA, so the discrepancy between measured and PMF-reconstructed $f_{60}$ is larger than indicated by the BBOA spectrum. Additionally, slight increases in the BBOA factor are observed during periods uninfluenced by biomass burning (e.g. in Fig. 8a), while the acetonitrile and $\mathrm{m} / \mathrm{z} 39$ concentrations are more than an order of magnitude 


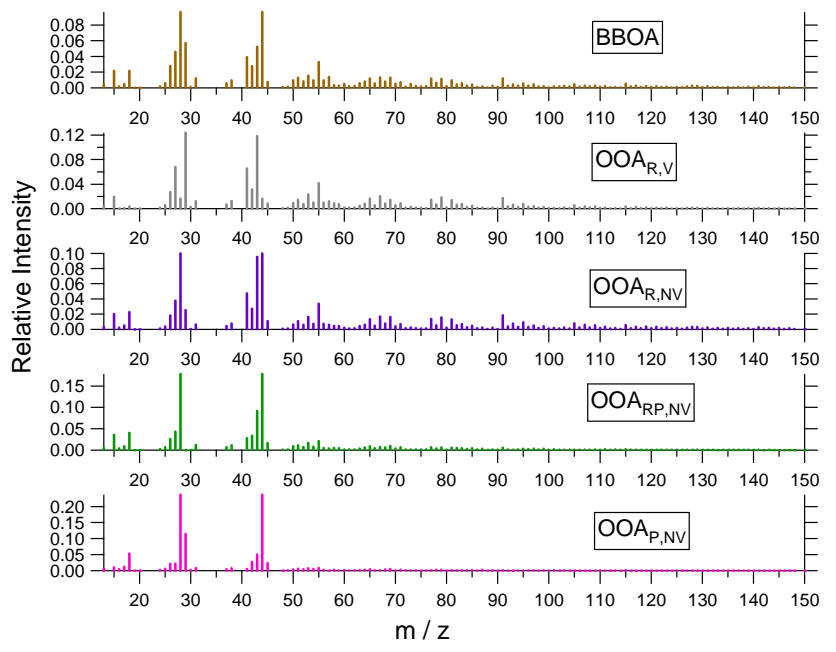

Fig. 9. Factor mass spectra from the 5-factor PMF solution to the TPOT AMS dataset. Mass spectra are normalized so that the sum of each spectrum equals 1 .

lower. All these observations suggest that the BBOA factor is slightly mixed with other sources.

The other four factors can all be classified as subtypes of oxygenated organic aerosol (OOA) and are distinguished by their volatility and reactive behavior. We denote these factors as $\mathrm{OOA}_{\mathrm{R}, \mathrm{V}}, \mathrm{OOA}_{\mathrm{R}, \mathrm{NV}}, \mathrm{OOA}_{\mathrm{RP}, \mathrm{NV}}$, and $\mathrm{OOA}_{\mathrm{P}, \mathrm{NV}}$, where the first subscript describes reactivity (" $R$ " = consumed by reaction with $\mathrm{OH}$, "RP" = may react with or be produced by $\mathrm{OH}$, "P" = produced by reaction with $\mathrm{OH}$ ), and the second subscript describes volatility ("V"= volatile in the TPOT, "NV"= non-volatile in the TPOT). Note that volatility is operationally defined from the $\sim 4{ }^{\circ} \mathrm{C}$ increase in temperature from the TPOT lamp, as discussed in Sect. 3.1. Thus, for example, $\mathrm{OOA}_{\mathrm{R}, \mathrm{V}}$ is both reactive and volatile. This is evident in Fig. 8 from the decreased $\mathrm{OOA}_{\mathrm{R}, \mathrm{V}}$ mass going from the Amb to AmbUV conditions, and further decrease from AmbUV to AmbUVOH. The figure shows that $O_{\mathrm{OOA}} \mathrm{V}$ is the only factor affected by the Amb/AmbUV transition. However, $\mathrm{OH}$ exposure causes a strong decrease in $\mathrm{OOA}_{\mathrm{R}, \mathrm{NV}}$, and produces $\mathrm{OOA}_{\mathrm{P}, \mathrm{NV}}$. Depending on the $\mathrm{OH}$ exposure, $\mathrm{OOA}_{\mathrm{RP}, \mathrm{NV}}$ may be produced (right-hand side of Fig. $8 \mathrm{a}$ and b), unaffected (left-hand side of Fig. 8b), or reacted away (not shown here but discussed later in conjunction with Fig. 10).

The PMF factor mass spectra are shown in Fig. 9. Among the OOA factors, the $f_{44}$ value (which correlates with $\mathrm{O}: \mathrm{C}$ ), is at its minimum for the volatile component $\mathrm{OOA}_{R, V} \quad\left(f_{44}=0.016\right)$. Within the $\mathrm{NV}$ components, $f_{44}$ increases as the factors move from reactants to products $\left(f_{44}\left(\mathrm{OOA}_{\mathrm{R}, \mathrm{NV}}\right)=0.10\right.$; $\left.f_{44}\left(\mathrm{OOA}_{\mathrm{RP}, \mathrm{NV}}\right)=0.18 ; f_{44}\left(\mathrm{OOA}_{\mathrm{P}, \mathrm{NV}}\right)=0.24\right)$. This provides direct evidence linking $\mathrm{O}: \mathrm{C}$ with both volatility and reaction progress. A second trend in the mass spectra is the prevalence of fragments at higher $\mathrm{m} / \mathrm{z}$ for the more reactive and volatile species. As shown in the Supplement (Figs. S7

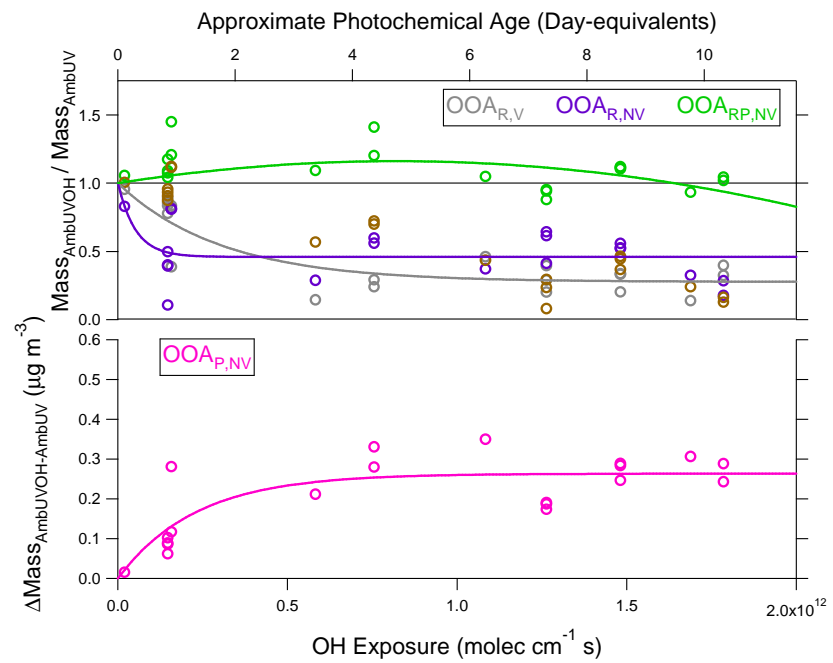

Fig. 10. Effect of $\mathrm{OH}$ exposure on PMF factor concentrations. Changes in factor mass are shown as the ratio of AmbUVOH to AmbUV conditions for $\mathrm{OOA}_{\mathrm{R}, \mathrm{V}}, \mathrm{OOA}_{\mathrm{R}, \mathrm{NV}}$, and $\mathrm{OOA}_{\mathrm{RP}, \mathrm{NV}}$ (top panel) and as the difference between these conditions for OOA $\mathrm{P}, \mathrm{NV}$ (bottom panel) due to the sometimes low AmbUV mass concentrations for this factor. Photochemical age is estimated assuming a mean $\mathrm{OH}$ concentration of $2 \times 10^{6}$ molec cm $^{-3}$. OOA, $\mathrm{V}$, $\mathrm{OOA}_{\mathrm{R}, \mathrm{NV}}$, and $\mathrm{OOA}_{\mathrm{P}, \mathrm{NV}}$ are fitted to $y=1+a\left(1-e^{-k x}\right)$, while $\mathrm{OOA}_{\mathrm{RP}, \mathrm{NV}}$ is fitted to a $3^{r d}$-order polynomial.

and $\mathrm{S} 8$ in the Supplement), the $\mathrm{OOA}_{R, V}$ and $\mathrm{OOA}_{R, N V}$ spectra are both quite similar to semi-volatile oxygenated organic aerosol SV-OOA spectra resolved from conventional PMF analyses, while the $\mathrm{OOA}_{\mathrm{NR}, \mathrm{NV}}$ and $\mathrm{OOA}, \mathrm{PV}$ spectra are more similar to previously reported LV-OOA ( $\mathrm{Ng}$ et al., 2011b). The BBOA factor shows somewhat elevated signal at $m / z 60$ and 73, which both individually constitute $\sim 0.5 \%$ of the total organic signal. These $\mathrm{m} / \mathrm{z}$ result from fragmentation of cellulose pyrolysis products such as levoglucosan and are frequently used as tracers for biomass burning influence in AMS spectra. The contributions of these two $\mathrm{m} / \mathrm{z}$ to the BBOA spectrum are larger by approximately a factor of 2 or more than their contributions to any other factor.

Figure 10 shows the effect of $\mathrm{OH}$ exposure on TPOT PMF factor mass concentrations. The BBOA, $\mathrm{OOA}_{\mathrm{R}, \mathrm{V}}, \mathrm{OOA}_{\mathrm{R}, \mathrm{NV}}$, and $\mathrm{OOA}_{\mathrm{RP}, \mathrm{NV}}$ are shown as the ratio of mass concentrations for the AmbUVOH to AmbUV conditions. For $\mathrm{OOA}_{\mathrm{P}, \mathrm{NV}}$, the difference between AmbUVOH and AmbUV mass concentrations is instead shown because of the sometimes low AmbUV OOA $\mathrm{P}, \mathrm{NV}$ concentrations, which lead to very high and scattered AmbUVOH/AmbUV ratios. The top panel shows a decrease in BBOA, $\mathrm{OOA}_{\mathrm{R}, \mathrm{V}}$ and $\mathrm{OOA}_{\mathrm{R}, \mathrm{NV}}$ mass for all $\mathrm{OH}$ exposures. $\mathrm{OOA}_{R, V}$ and $\mathrm{OOA}_{\mathrm{R}, \mathrm{NV}}$ are shown to be quite reactive, although there is a great deal of scatter in the measurements. Reaction at this initial stage may depend strongly on details of the particle composition. Similar to the behavior of individual $\mathrm{m} / \mathrm{z}$ shown in 


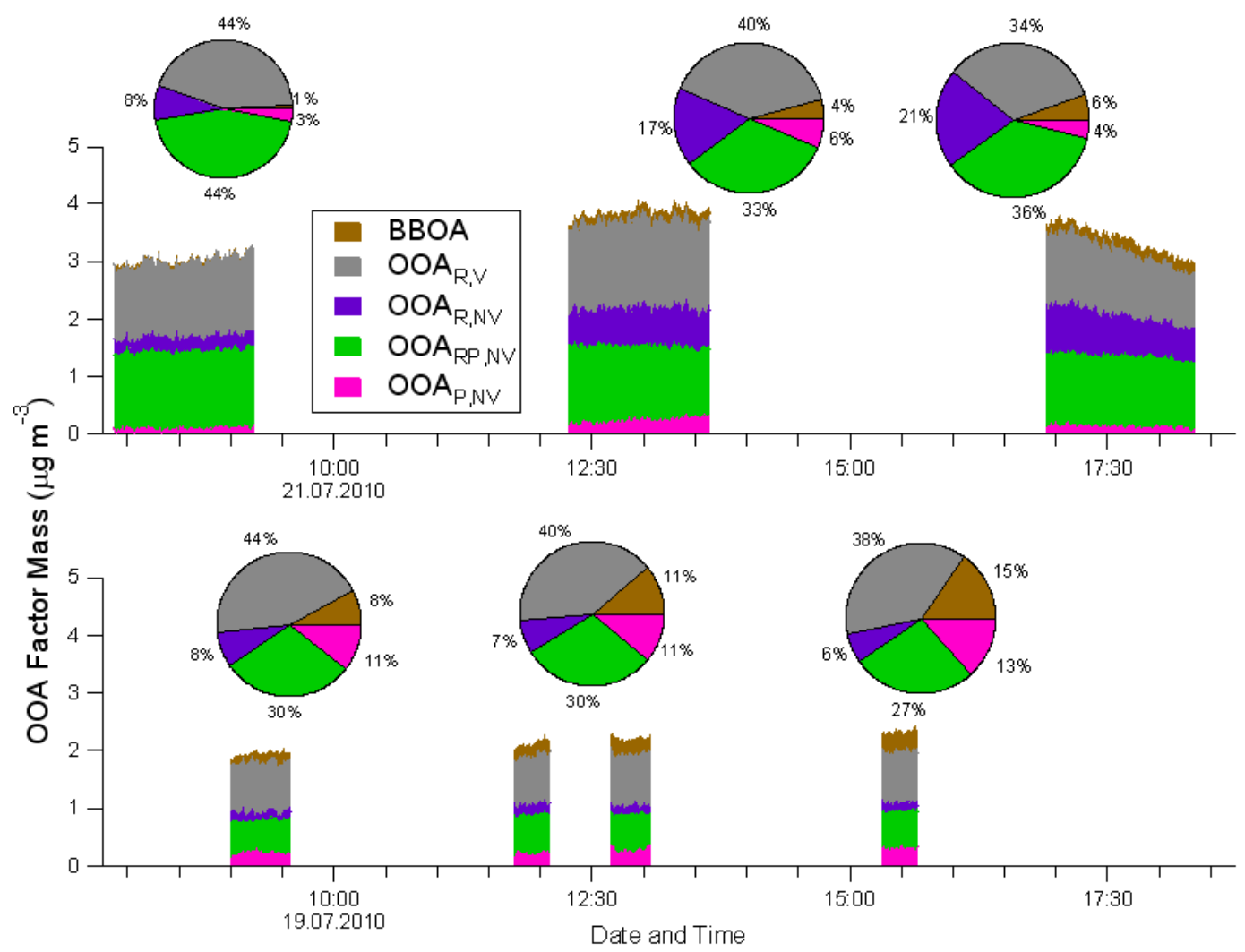

Fig. 11. Ambient organic aerosol composition (i.e. Amb condition) in terms of TPOT PMF factors. The stacked factor time series equal the total organic mass.

Fig. 6, most of the decrease in $\mathrm{OOA}_{R, V}(\sim 75 \%$ consumed $)$ and $\mathrm{OOA}_{\mathrm{R}, \mathrm{NV}}(\sim 50 \%$ consumed $)$ occurs within $\sim 3$ dayequivalents of photochemical aging. The reactivity of these factors suggests that ambient SV-OOA, which has a similar mass spectrum, may also react quite quickly in the atmosphere. Aging-induced reductions in SV-OOA-like species have previously been observed for airmasses in southwestern Ontario, Canada (Slowik et al., 2011).

Somewhat different behavior is observed for BBOA. While $\sim 35 \%$ of BBOA is consumed within $\sim 3$ dayequivalents, this value continues to increase, reaching $\sim 60 \%$ or more after $\sim 6$ day-equivalents of exposure. This indicates that BBOA is not a fully conserved tracer for the AMS, consistent with both the spectral changes in Fig. 6 and ambient studies of biomass burning plumes (Capes et al., 2008). The figure does not show evidence for significant decreases in BBOA for less than $\sim 1$ day-equivalent of aging.

A further contrast is observed for the $\mathrm{OOA}_{\mathrm{RP}, \mathrm{NV}}$ factor. Here an increase in mass on the order of $\sim 20 \%$ is observed during approximately the first 3 day-equivalents of aging. However, higher exposures yield no net change relative to the unreacted concentrations. This suggests that $\mathrm{OOA}_{\mathrm{RP}, \mathrm{NV}}$ can be considered an early- or intermediate-stage reaction product, but itself reacts given sufficiently high $\mathrm{OH}$ exposures. On the other hand, while $\mathrm{OOA}_{\mathrm{P}, \mathrm{NV}}$ forms rapidly, with most production occurring, within $\sim 3$ day-equivalents of aging, there is no evidence for its consumption within the range of exposures studied, suggesting that the end product of particle-phase oxidation resembles $\mathrm{OOA}_{\mathrm{P}, \mathrm{NV}}$. As noted previously, $\mathrm{OOA}_{\mathrm{P}, \mathrm{NV}}$ is spectrally similar to AMS LV-OOA spectra. Figure 10 thus supports the current understanding that atmospheric aging pushes aerosols of varying composition towards an LV-OOA-like state (Ng et al., 2010; Jimenez et al., 2009). The figure also indicates that heterogeneous oxidation and/or gas-phase oxidation of organic material partitioning between the particle and gas phase can significantly affect both primary and secondary aerosol components on atmospherically-relevant timescales.

The TPOT PMF analysis discussed above can also provide insight into the composition and volatility/reactivitybased properties of the (unreacted) ambient aerosol. Figure 11 shows the TPOT PMF representation of particle composition for 19 and 21 July. These days take place during the early and late stages, respectively, of a period of increasing temperatures, biogenic emissions, and biogenic SOA. On 19 July (lower panel), when the temperature and biogenic emissions are lower (daily maximum temperature $\sim 19^{\circ} \mathrm{C}$ ), there is lower total organic mass and changes to the composition during the day are negligible. In contrast, 21 July (maximum temperature $\sim 23^{\circ} \mathrm{C}$ ) shows a $50-100 \%$ increase 
in the total organic mass and changes in composition relative to those on 19 July at the same time of day. Peak concentrations of organic aerosol, biogenic VOCs, and $\mathrm{OH}$ radicals all occur during mid to late afternoon (Macdonald et al., 2012), and the strong diurnal patterns observed for these species are consistent with local production. Figure 11 shows that the increase in organic aerosol mass during the day on 21 July caused by local production primarily yields increases in the $\mathrm{OOA}_{R, N V}$ and $\mathrm{OOA}_{\mathrm{RP}, \mathrm{NV}}$ components. $\mathrm{OOA}_{\mathrm{R}, \mathrm{V} \text {-like }}$ compounds may also be produced, but the increased midday temperatures could prevent them from significantly partitioning to the particle. A small increase in $\mathrm{OOA}_{\mathrm{P}, \mathrm{NV}}$ during the middle of the day on 21 July is also evident. While highly oxygenated, LV-OOA-like factors such as $\mathrm{OOA}_{R P, N V}$ and $\mathrm{OOA}_{\mathrm{P}, \mathrm{NV}}$ are frequently associated with long-range transport, the evidence presented in Figs. 10 and 11 suggests that they may also form during rapid local production in some cases. This is consistent with rapid formation of highly oxidized SOA observed in polluted airmasses in southwestern Ontario, Canada (Slowik et al., 2011).

Coupling the reactivity/volatility-based description of ambient aerosol composition shown in Fig. 11 with the PMF factor reactivity characterization in Fig. 10 enables a detailed description of the present aerosol composition. Using such reactivity and volatility coordinates makes for easier comparison to the framework presented by Jimenez et al. (2009) for the aging of organic aerosols. It also enables projection of the future changes in composition during the particle's atmospheric lifetime (albeit neglecting future SOA formation from gas-phase precursors due to TPOT SOA yield properties). Accessing such a description requires online manipulation of the aerosol composition by a system such as the TPOT; the information is not directly accessible using conventional ambient measurements. This suggests that controlled manipulation of ambient aerosol may be a useful tool for characterizing particle properties and predicting their evolution during the course of atmospheric aging. Such an approach has been applied to laboratory-generated SOA from $\alpha$-pinene ozonolysis (at concentrations many times higher than ambient) (George and Abbatt, 2010), yielding reactantand product-like PMF factors (see Figs. S8 and S9 in the Supplement). The mass spectrum of the reactant-like factor is quite similar to $\mathrm{OOA}_{\mathrm{R}, \mathrm{V}}$, however its volatility is unknown. Interestingly, the product-like factor mass spectrum is similar to $\mathrm{OOA}_{\mathrm{RP}, \mathrm{NV}}$ rather than $\mathrm{OOA}_{\mathrm{P}, \mathrm{NV}}$. This is consistent with the trend towards decreased $\mathrm{OH}$-induced spectral changes for $\alpha$-pinene ozonolysis SOA relative to the biogenic SOA; for example, George and Abbatt (2010) observed little effect of $\mathrm{OH}$ on $\mathrm{m} / \mathrm{z}$ 43, while for biogenic SOA a significant decrease is observed (see Fig. 6). Further experiments are required to fully elucidate the effects of the initial particle composition on reaction products and pathways.

The general approach herein, in which PMF analysis is performed on organic aerosol subject to forced changes in the chemical and/or physical environment (e.g. temperature or relative humidity), could be applied more widely to better determine the nature of organic particulates. However, this approach does add to the complexity of the data analysis. The present analysis is simplified by the dominance of a single source class (biogenic SOA). Other locations may have more source complexity, however it is not necessary to apply PMF to an entire dataset at once. Rather, periods characteristic of particular source/aerosol types can be analyzed separately (e.g. if biomass burning periods were more prevalent in the current study, separate TPOT PMF analyses could be performed on biogenic and biomass burningdominated periods). For each period segregated in this way, the UV/oxidation-based variability remains, and these properties would likely still be reflected in the retrieved PMF factors.

\section{Conclusions}

We present the first field deployment of the Toronto Photooxidation Tube (TPOT), a field-deployable flow reactor for the controlled $\mathrm{OH}$ oxidation of ambient aerosol. The deployment took place during summer in a forested location strongly influenced by biogenic organic aerosol formation during warm periods. Aerosols were continuously sampled, alternating between three conditions: (1) unreacted ambient aerosol ("Amb"); (2) ambient aerosol UV light and subjected to a $\sim 4$ to $10^{\circ} \mathrm{C}$ temperature increase ("AmbUV"); and (3) ambient aerosol additionally subjected to $\mathrm{OH}$ exposures ranging from approximately $2 \times 10^{10}$ to $2 \times 10^{12}$ molec cm ${ }^{-3} \mathrm{~s}$ ("AmbUVOH"), corresponding to up to $\sim 10$ day-equivalents of atmospheric photochemical aging. Particle mass and composition were monitored with a time-of-flight aerosol mass spectrometer (C-ToF-AMS). Due in large part to the geometry of the TPOT system, significant SOA generation was not observed and the dominant reactive processes were instead heterogeneous oxidation and/or gas-phase reaction of semivolatile species partitioning from the particle to the gas phase.

The AmbUV condition caused a reduction in the organic mass on the order of 10 to $25 \%$, depending on the oxygenation of the unperturbed aerosol. Reaction with $\mathrm{OH}$ caused further decreases in the organic mass on the order of up to an additional $25 \%$. Similar decreases were observed throughout the mass spectrum, with the exception of $m / z 44\left(\mathrm{CO}_{2}^{+}\right.$ion $)$ and $m / z 45$.

Positive matrix factorization analysis of the TPOT AMS organic mass spectra yielded a primary biomass burning factor and four oxygenated organic aerosol factors directly related to reactivity and volatility. This classification of aerosol components is enabled by the TPOT-modulated perturbation of aerosol composition, and is not otherwise accessible. Analysis of the PMF factors and individual $\mathrm{m} / \mathrm{z}$ both indicate rapid formation of highly oxygenated organic aerosol, likely with a strong contribution from organic acid functional 
groups. Evidence for early/intermediate-stage $\mathrm{OH}$ reaction products is also observed. $\mathrm{OH}$ oxidation significantly affects particle composition even for exposures corresponding to $<1$ day-equivalent of atmospheric aging, and most reaction with biogenic SOA appears complete after $\sim 3$ day-equivalents. The particle-phase reaction end products have mass spectra similar to the low-volatility oxygenated organic aerosol (LVOOA) factors widely reported in the literature (e.g. Zhang et al., 2005; Lanz et al., 2007; Jimenez et al., 2009; Ulbrich et al., 2009), thus providing supporting evidence that aged organic aerosol does arise through $\mathrm{OH}$-driven oxidation processes. This general approach of PMF analysis of organic aerosol subject to forced changes in the chemical and/or physical environment (e.g. temperature or relative humidity), could be applied more widely to better determine the nature of organic particulates.

\section{Supplementary material related to this article is available online at: http://www.atmos-chem-phys.net/12/ 9775/2012/acp-12-9775-2012-supplement.pdf.}

Acknowledgements. The authors gratefully acknowledge planning and logistical support from Anne Marie Macdonald and Richard Leaitch (Environment Canada). Steven Sjostedt (Environment Canada) assisted with the MEK calibrations. PTR-MS data was provided by S. Sjostedt and A. Macdonald. We also thank John Liggio (Environment Canada) for helpful discussion of highresolution AMS spectra. Funding was provided by Environment Canada, NSERC, and CFCAS-CAFC. Environment Canada funded the Whistler Aerosol and Cloud Study 2010 through the Clean Air Regulatory Agenda (CARA). Co-operation and support from Whistler-Blackcomb is gratefully acknowledged.

Edited by: B. Ervens

\section{References}

Aiken, A. C., DeCarlo, P. F., Kroll, J. H., Worsnop, D. R., Huffman, J. A., Docherty, K. S., Ulbrich, I. M., Mohr, C., Kimmel, J. R., Sueper, D., Sun, Y., Zhang, Q., Trimborn, A., Northway, M., Ziemann, P. J., Canagaratna, M. R., Onasch, T. B., Alfarra, M. R., Prevot, A. S. H., Dommen, J., Duplissy, J., Metzger, A., Baltensperger, U., and Jimenez, J. L.: O/C and OM/OC ratios of primary, secondary, and ambient organic aerosols with highresolution time-of-flight mass spectrometry, Environ. Sci. Technol., 42, 4478-4485, 2008.

Allan, J. D., Jimenez, J. L., Williams, P. I., Alfarra, M. R., Bower, K. N., Jayne, J. T., Coe, H., and Worsnop, D. R.: Quantitative sampling using an Aerodyne aerosol mass spectrometer 1: Techniques of data interpretation and error analysis, J. Geophys. Res., 108, 4090, doi:10.1029/2002JD002358, 2003.

Canagaratna, M. R., Jayne, J. T., Jimenez, J. L., Allan, J. D., Alfarra, M. R., Zhang, Q., Onasch, T. B., Drewnick, F., Coe, H., Middlebrook, A., Delia, A., Williams, L. R., Trimborn, A. M., Northway, M. J., DeCarlo, P. F., Kolb, C. E., Davidovits, P., and
Worsnop, D. R.: Chemical and microphysical characterization of ambient aerosols with the Aerodyne aerosol mass spectrometer, Mass Spec. Rev., 26, 185-222, 2007.

Capes, G., Johnson, B., McFiggans, G., Williams, P. I., Haywood, J., and Coe, H.: Aging of biomass burning aerosols over West Africa: Aircraft measurements of chemical composition, microphysical properties, and emission ratios, J. Geophys. Res., 113, D00C15, doi:10.1029/2008JD009845, 2008.

Chirico, R., DeCarlo, P. F., Heringa, M. F., Tritscher, T., Richter, R., Prévôt, A. S. H., Dommen, J., Weingartner, E., Wehrle, G., Gysel, M., Laborde, M., and Baltensperger, U.: Impact of aftertreatment devices on primary emissions and secondary organic aerosol formation potential from in-use diesel vehicles: results from smog chamber experiments, Atmos. Chem. Phys., 10, 11545-11563, doi:10.5194/acp-10-11545-2010, 2010.

Chow, J. C., Watson, J. G., Lowenthal, D. H., Chen, L. W. A., Zielinska, B., Mazzoleni, L. R., and Magliano, K. L.: Evaluation of organic markers for chemical mass balance source apportionment at the Fresno Supersite, Atmos. Chem. Phys., 7, 17411754, doi:10.5194/acp-7-1741-2007, 2007.

Christensen, W. F., Schauer, J. J., and Lingwall, J. W.: Iterated confirmatory factor analysis for pollution source apportionment, Environmetrics, 17, 663-681, 2006.

Cubison, M. J., Ortega, A. M., Hayes, P. L., Farmer, D. K., Day, D., Lechner, M. J., Brune, W. H., Apel, E., Diskin, G. S., Fisher, J. A., Fuelberg, H. E., Hecobian, A., Knapp, D. J., Mikoviny, T., Riemer, D., Sachse, G. W., Sessions, W., Weber, R. J., Weinheimer, A. J., Wisthaler, A., and Jimenez, J. L.: Effects of aging on organic aerosol from open biomass burning smoke in aircraft and laboratory studies, Atmos. Chem. Phys., 11, 12049-12064, doi:10.5194/acp-11-12049-2011, 2011.

de Gouw, J. and Jimenez, J. L.: Organic Aerosols in the Earth's Atmosphere, Environ. Sci. Technol., 43, 7614-7618, 2009.

Drewnick, F., Hings, S. S., DeCarlo, P. F., Jayne, J. T., Gonin, M., Fuhrer, K., Weimer, S., Jimenez, J. L., Demerjia, K. L., Borrman, S., and Worsnop, D. R.: A new time-of-flight aerosol mass spectrometer (ToF-AMS) - Instrument description and first field deployment, Aerosol Sci. Technol., 39, 637-658, 2005.

Duplissy, J., DeCarlo, P. F., Dommen, J., Alfarra, M. R., Metzger, A., Barmpadimos, I., Prevot, A. S. H., Weingartner, E., Tritscher, T., Gysel, M., Aiken, A. C., Jimenez, J. L., Canagaratna, M. R., Worsnop, D. R., Collins, D. R., Tomlinson, J., and Baltensperger, U.: Relating hygroscopicity and composition of organic aerosol particulate matter, Atmos. Chem. Phys., 11, 11551165, doi:10.5194/acp-11-1155-2011, 2011.

Farmer, D. K., Matsunaga, A., Docherty, K. S., Surratt, J. D., Seinfeld, J. H., Ziemann, P. J., and Jimenez, J. L.: Response of an aerosol mass spectrometer to organonitrates and organosulfates and implications for atmospheric chemistry, Proc. Natl. Acad. Sci., 107, 6670-6675, 2010.

George, I. J., Vlasenko, A., Slowik, J. G.., Broekhuizen, K., and Abbatt, J. P. D.: Heterogeneous oxidation of saturated organic aerosols by hydroxyl radicals: uptake kinetics, condensed-phase products, and particle size change, Atmos. Chem. Phys., 7, 41874201, doi:10.5194/acp-7-4187-2007, 2007.

George, I. J., Slowik, J., and Abbatt, J. P. D.: Chemical aging of ambient organic aerosol from heterogeneous reaction with hydroxyl radicals, Geophys. Res. Lett., 35, L13811, doi:10.1029/2008GL033884, 2008. 
Grieshop, A. P., Logue, J. M., Donahue, N. M., and Robinson, A. L.: Laboratory investigation of photochemical oxidation of organic aerosol from wood fires - Part 1: Measurement and simulation of organic aerosol evolution, Atmos. Chem. Phys., 9, 1263-1277, doi:10.5194/acp-9-1263-2009, 2009.

Hallquist, M., Wenger, J. C., Baltensperger, U., Rudich, Y., Simpson, D., Claeys, M., Dommen, J., Donahue, N. M., George, C., Goldstein, A. H., Hamilton, J. F., Herrmann, H., Hoffmann, T., Iinuma, Y., Jang, M., Jenkin, M. E., Jimenez, J. L., KiendlerScharr, A., Maenhaut, W., McFiggans, G., Mentel, T. F., Monod, A., Prévôt, A. S. H., Seinfeld, J. H., Surratt, J. D., Szmigielski, R., and Wildt, J.: The formation properties and impact of secondary organic aerosol: current and emerging issues, Atmos. Chem. Phys., 9, 5155-5236, doi:10.5194/acp-9-5155-2009, 2009.

Hannigan, M. P., Busby Jr., W. F., and Cass, G. R.: Source contributions to the mutagenicity of urban particulate air pollution, J. Air Waste Manage. Assoc., 55, 399-410, 2005.

Heald, C. L., Kroll, J. H., Jimenez, J. L., Docherty, K. S., DeCarlo, P. F., Aiken, A. C., Chen, Q., Martin, S. T., Farmer, D. K., and Artaxo, P.: A simplified description of the evolution of organic aerosol composition in the atmosphere, Geophys. Res. Lett., 37, L08803, doi:10.1029/2010GL042737, 2010.

Hidy, G. M. and Friedlander, S. K.: The nature of the Los Angeles aerosol, Proceedings of the Second International Clean Air Congress, edited by: Englund, H. M. and Beery, W. T., 391-404, 1971.

Huffman, J. A., Docherty, K. S., Mohr, C., Cubison, M. J., Ulbrich, I. M., Ziemann, P. J., Onasch, T. B., and Jimenez, J. L.: Chemically-resolved volatility measurements of organic aerosol from different sources, Environ. Sci. Technol., 43, 5351-5357, doi:10.1021/es803539d, 2009.

Jimenez, J. L., Canagaratna, M. R., Donahue, N. M., Prevot, A. S. H., Zhang, Q., Kroll, J. H., DeCarlo, P. F., Allan, J. D., Coe, H., Ng., N. L., Aiken, A. C., Docherty, K. D., Ulbrich, I. M., Grieshop, A. P., Robinson, A. L., Duplissy, J., Smith, J. D., Wilson, K. R., Lanz, V. A., Hueglin, C., Sun, Y. L., Tian, J., Laaksonen, A., Raatikainen, T., Rautiainen, J., Vaattovaara, P., Ehn, M., Kulmala, M., Tomlinson, J. M., Collins, D. R., Cubison, M. J., Dunlea, E. J., Huffman, J. A., Onasch, T. B., Alfarra, M. R., Williams, P. I., Bower, K., Kondo, Y., Schneider, J., Drewnick, F., Borrmann, S., Weimer, S., Demerjian, K., Salcedo, D., Cottrell, L., Griffin, R., Takami, A., Miyoshi, T., Hatakeyama, S., Shimono, A., Sun, J. Y., Zhang, Y. M., Dzepina, K., Kimmel, J. R., Sueper, D., Jayne, J. T., Herndon, S. C., Trimborn, A. M., Williams, L. R., Wood, E. C., Kolb, C. E., Middlebrook, A. M., Baltensperger, U., and Worsnop, D. R.: Evolution of organic aerosols in the atmosphere, Science, 326, 1525-1529, 2009.

Kanakidou, M., Seinfeld, J. H., Pandis, S. N., Barnes, I., Dentener, F. J., Facchini, M. C., Van Dingenen, R., Ervens, B., Nenes, A., Nielsen, C. J., Swietlicki, E., Putaud, J. P., Balkanski, Y., Fuzzi, S., Horth, J., Moortgat, G. K., Winterhalter, R., Myhre, C. E. L., Tsigaridis, K., Vignati, E., Stephanoou, E. G., and Wilson, J.: Organic aerosol and global climate modelling: a review, Atmos. Chem. Phys., 5, 1053-1123, doi:10.5194/acp-5-1053-2005, 2005.

Kang, E., Toohey, D. W., and Brune, W. H.: Dependence of SOA oxidation on organic aerosol mass concentration and $\mathrm{OH}$ exposure: experimental PAM chamber studies, Atmos. Chem. Phys.,
11, 1837-1852, doi:10.5194/acp-11-1837-2011, 2011.

Kessler, S. H., Smith, J. D., Che, D. L., Worsnop, D. R., Wilson, K. R., and Kroll, J. H.: Chemical sinks of organic aerosol: kinetics and products of the heterogeneous oxidation of erythritol and levoglucosan, Environ. Sci. Technol., 44, 7005-7010, doi:10.1021/es101465m, 2010.

Kroll, J. H., Smith, J. D., Che, D. L., Kessler, S. H., Worsnop, D. R., and Wilson, K. R.: Measurement of fragmentation and functionalization pathways in the heterogeneous oxidation of oxidized organic aerosol, Phys. Chem. Chem. Phys., 11, 8005-8014, 2009.

Lambe, A. T., Ahern, A. T., Williams, L. R., Slowik, J. G., Wong, J. P. S., Abbatt, J. P. D., Brune, W. H., Ng, N. L., Wright, J. P., Croasdale, D. R., Worsnop, D. R., Davidovits, P., and Onasch, T. B.: Characterization of aerosol photooxidation flow reactors: heterogeneous oxidation, secondary organic aerosol formation and cloud condensation nuclei activity measurements, Atmos. Meas. Tech., 4, 445-461, doi:10.5194/amt-4-445-2011, 2011a.

Lambe, A. T., Onasch, T. B., Massoli, P., Croasdale, D., Wright, J. P., Ahern, A. T., Williams, L. R., Worsnop, D. R., Brune, W. H., and Davidovits, P.: Laboratory studies of the chemical composition and cloud condensation nuclei (CCN) activity of secondary organic aerosol (SOA) and oxidized primary organic aerosol (OPOA), Atmos. Chem. Phys., 11, 8913-8928, doi:10.5194/acp11-8913-2011, $2011 \mathrm{~b}$.

Lanz, V. A., Alfarra, M. R., Baltensperger, U., Buchmann, B., Hueglin, C., and Prevot, A. S. H.: Source apportionment of submicron organic aerosols at an urban site by factor modelling of aerosol mass spectra, Atmos. Chem. Phys., 7, 1503-1522, doi:10.5194/acp-7-1503-2007, 2007.

Leaitch, W. R., Macdonald, A. M., Anlauf, K. G., Liu, P. S. K., Toom-Sauntry, D., Li, S.-M., Liggio, J., Hayden, K., Wasey, M. A., Russell, L. M., Takahama, S., Liu, S., van Donkelaar, A., Duck, T., Martin, R. V., Zhang, Q., Sun., Y., McKendry, I., Shantz, N. C., and Cubison, M.: Evidence for Asian dust effects from aerosol plume measurements during INTEXB 2006 near Whistler, BC, Atmos. Chem. Phys., 9, 3523-3546, doi:10.5194/acp-9-3523-2009, 2009.

Leaitch, W. R., Macdonald, A. M., Brickell, P. C., Liggio, J., Sjostedt, S. J., Vlasenko, A., Bottenheim, J. W., Huang, L., Li, S.-M., Liu, P. S. K., Toom-Sauntry, D., Hayden, K. A., Shantz, N. C., Wiebe, H. A., Zhang, W., Abbatt, J. P. D., Slowik, J. G., Chang, R. Y.-W., Russell, L. M., Schwartz, R. E., Jayne, J. T., and Ng, N. L.: Temperature response of organic aerosol from temperate forests, Atmos. Environ., 45, 6696-6704, 2011.

Macdonald, A. M., Leaitch, W. R., Liggio, J., Sjostedt, S. J., Wiebe, H. A., Wentzell, J., Stupple, G.., Vlasenko, A., Hayden, K. H., Li, S.-M., Strawbridge, K., Al-Basheer, W., Liu, P. S. K., ToomSauntry, D., Sharma, S., Mihele, C., Abbatt, J. P. D., Slowik, J. G.., Lee, A. K. Y., Wong, J. P. S., Russell, L. M., Ahlm, L., Bertram, A., Schroder, J., Campuzano-Jost, P., Herckes, P., Wang, Y., Pierce, J., Wainwright, C., Noone, K., Cziczo, D., Chan, E., Corbin, J., Buller, J., Sheppard, A., and Elford, A.: Overview of the 2010 Whistler Aerosol and Cloud Study, in preparation, 2012.

Mentel, T. F., Wildt, J., Kiendler-Scharr, A., Kleist, E., Tillmann, R., Dal Maso, M., Fisseha, R., Hohaus, T., Spahn, H., Uerlings, R., Wegener, R., Griffiths, P. T., Dinar, E., Rudich, Y., and Wahner, A.: Photochemical production of aerosols from real plant emissions, Atmos. Chem. Phys., 9, 4387-4406, doi:10.5194/acp-9- 
4387-2009, 2009.

Ng, N. L., Canagaratna, M. R., Zhang, Q., Jimenez, J. L., Tian, J., Ulbrich, I. M., Kroll, J. H., Docherty, K. S., Chhabra, P. S., Bahreini, R., Murphy, S. M., Seinfeld, J. H., Hildebrandt, L., Donahue, N. M., DeCarlo, P. F., Lanz, V. A., Prévôt, A. S. H., Dinar, E., Rudich, Y., and Worsnop, D. R.: Organic aerosol components observed in Northern Hemispheric datasets from Aerosol Mass Spectrometry, Atmos. Chem. Phys., 10, 46254641, doi:10.5194/acp-10-4625-2010, 2010.

Ng, N. L., Canagaratna, M. R., Jimenez, J. L., Chhabra, P. S., Seinfeld, J. H., and Worsnop, D. R.: Changes in organic aerosol composition with aging inferred from aerosol mass spectra, Atmos. Chem. Phys., 11, 6465-6474, doi:10.5194/acp-11-64652011, 2011a.

Ng, N. L., Canagaratna, M. R., Jimenez, J. L., Zhang, Q., Ulbrich, I. M., and Worsnop, D. R.: Real-time methods for estimating organic component mass concentrations from aerosol mass spectrometer data, Environ. Sci. Technol., 45, 910-916, $2011 \mathrm{~b}$.

Paatero, P.: Least squares formulation of robust non-negative factor analysis, Chemom. Intell. Lab. Syst., 37, 23-35, 1997.

Paatero, P. and Tapper, U.: Positive matrix factorization: A nonnegative factor model with optimal utilization of error estimates of data values, Environmetrics, 5, 111-126, 1994.

Schauer, J. J., Rogge, W. F., Mazurek, M. A., Hildemann, L. M., Cass, G. R., and Simoneit, B. R.: Source apportionment of airborne particulate matter using organic compounds as tracers, Atmos. Environ., 30, 3837-3855, 1996.

Schwartz, R. E., Russell, L. M., Sjostedt, S. J., Vlasenko, A., Slowik, J. G., Abbatt, J. P. D., Macdonald, A. M., Li., S.M., Liggio, J., Toom-Sauntry, D., and Leaitch, W. R.: Biogenic oxidized organic functional groups in aerosol particles from a mountain forest site and their similarities to laboratory chamber products, Atmos. Chem. Phys., 10, 5075-5088, doi:10.5194/acp-10-50752010, 2010.

Slowik, J. G., Vlasenko, A., McGuire, M., Evans, G. J., and Abbatt, J. P. D.: Simultaneous factor analysis of organic particle and gas mass spectra: AMS and PTR-MS measurements at an urban site, Atmos. Chem. Phys., 10, 1969-1988, doi:10.5194/acp-10-19692010, 2010.

Slowik, J. G., Brook, J., Chang, R. Y.-W., Evans, G. J., Hayden, K., Jeong, C.-H., Li, S.-M., Liggio, J. L., Liu, P. S. K., McGuire, M., Mihele, C., Sjostedt, S., Vlasenko, A., and Abbatt, J. P. D.: Photochemical processing of organic aerosol at nearby continental sites: contrast between urban plumes and regional aerosol, Atmos. Chem. Phys., 11, 2991-3006, doi:10.5194/acp-11-29912011, 2011.
Sun, Y., Zhang, Q., Macdonald, A. M., Hayden, K., Li, S.-M., Liggio, J., Liu, P. S. K., Anlauf, K. G., Leaitch, W. R., Steffen, A., Cubison, M., Worsnop, D. R., van Donkelaar, A., and Martin, R. V.: Size-resolved aerosol chemistry on Whistler Mountain, Canada, with a high-resolution aerosol mass spectrometer during INTEX-B, Atmos. Chem. Phys., 9, 3095-3111, doi:10.5194/acp9-3095-2009, 2009.

Szmigielski, R., Surratt, J. D., Gómez-González, Y., Van der Veken, P., Kourtchev, I., Vermeylen, R., Blockhuys, F., Jaoui, M., Kleindienst, T. E., Lewandowski, M., Offenberg, J. H., Edney, E. O., Seinfeld, J. H., Maenhaut, W., and Claeys, M.: 3-methyl1,2,3-butanetricarboxylic acid: an atmospheric tracer for terpene secondary organic aerosol, Geophys. Res. Lett., 34, L24811, doi:10.1029/2007GL031338, 2007.

Takahama, S., Schwartz, R. E., Russell, L. M., Macdonald, A. M., Sharma, S., and Leaitch, W. R.: Organic functional groups in aerosol particles from burning and non-burning forest emissions at a high-elevation mountain site, Atmos. Chem. Phys., 11, 6367-6386, doi:10.5194/acp-11-6367-2011, 2011.

Ulbrich, I. M., Canagaratna, M. R., Zhang, Q., Worsnop, D. R., and Jimenez, J. L.: Interpretation of organic components from positive matrix factorization of aerosol mass spectrometric data, Atmos. Chem. Phys., 9, 2891-2918, doi:10.5194/acp-9-2891-2009, 2009.

Wahlin, P.: COPREM - A multivariate receptor model with a physical approach, Atmos. Environ., 37, 4861-4867, 2003.

Wong, J. P. S., Lee, A. K. Y., Slowik, J. G., Cziczo, D. J., Leaitch, W. R., Macdonald, A., and Abbatt, J. P. D.: Oxidation of ambient biogenic secondary organic aerosol by hydroxyl radicals: Effects on cloud condensation nuclei activity, Geophys. Res. Lett., 38, L22805, doi:10.1029/2011GL049351, 2011.

Zhang, Q., Alfarra, M. R., Worsnop, D. R., Allan, J. D., Coe, H., Canagaratna, M. R., and Jimenez, J. L.: Deconvolution and quantification of hydrocarbon-like and oxygenated organic aerosols based on aerosol mass spectrometry, Environ. Sci. Technol., 39, 4938-4952, 2005.

Zhao, W. X. and Hopke, P. K.: Source identification for fine aerosols in Mammoth Cave National Park, Atmos. Res., 80, 309-322, 2006. 